II.

\title{
Der Rapt de séduction als Ehehindernis nach gallikanischem Kirchenrecht.
}

\author{
Von \\ Herrn Dr. theol. Max Mitterer \\ in München. ${ }^{1}$ ) \\ $\S 1$. \\ Vorgeschichte.
}

In langem Ringen mit Anschauungen des römischen Rechts und der deutschen Stammesrechte hatte die Kirche den Grundsatz zur Anerkennung gebracht, daß die Ehen gewaltunterworfener Personen vom Willen der Gewalthaber rechtlich unabhängig sein sollten. Diese Regelung der schwierigen Frage erscheint als die bessere und richtigere, weil die Eheschließung eine höchstpersönliche Angelegenbeit der Kontrahenten ist. Das Kind, das unwiderruflich an den anderen Gatten gebunden bleibt, solange beide_am Leben sind, ist an der Wahl desselben in erster Linie interessiert, viel mebr als die Eltern oder gar etwaige Vormünder, und soll darum frei nach eigenem Ermessen die Entscheidung treffen können.

Allerdings schloß diese Freiheit der Kinder auch die Gefahr des Mißbrauches in sich, insbesondere deshalb, weil die Eheschließung an keinerlei notwendige Form gebunden

1) Die nachfolgende Studie wurde 1917/18 in München als Anhang zu einer auf Anregung und unter Leitung des verstorbenen Herrn Prof. Dr. Heinrich Maria Gietl ausgearbeiteten theologischen Doktordissertation: Geschiọte des Ehehindernisses der Entführung im kano nischen Rechte seit Gratian verfagt und, nachdem sie mit jener Herrn Prof. Dr. Eduard Eichmann inzwischen vorgelegen hatte, am 17. Fobruar 1922 im Kinchenrechtlichen Institut des Herrn Geheimrat Prof. D. Dr. Ulrich Stutz in Berlin anlëBlich einer nochmaligen Utberarbeitung vorgetragen. 
war, vielmehr auch die heimlichen, durch bloße verba de praesenti zustande gekommenen Ehen als gültig anerkannt wurden, obschon sie von der Kirche strengstens verboten und mit schweren Strafen bedroht waren. Zwar blieb selbstverständlich die sittliche Pflicht der Kinder bestehen, vor Eingehung einer Ehe die Eltern zu Rate zu ziehen und deren begründete Einwendungen zu beachten; aber sittliche Pflichten bilden, wenigstens in einer Zeit des Niedergangs, wie sie das ausgehende Mittelalter darstellt, keine genügende Schranke gegen die wilkle, sinnliche Leidenschaft.

In der Tat wurden denn auch die nie verstummten Klagen über die heimlichen Ehen und namentlich über grobe Mißachtung der elterlichen Autorität gegen Ende des Mittelalters immer lauter und das Bedürfnis nach gründlicher Abstellung der Übelstände immer dringender, zumal in Frankreich, sei es, daß dort die heimlichen Ehen häufiger als anderswo vorkamen, sei es, was wahrscheinlicher ist, daß man sie sich dort mehr zu Herzen nahm.

Abhilfe sollte das Konzil von Trient schaffen. Allein das Konzil, das sich schon im Jahre 1547 eingehend mit der Frage befaßte, konnte nicht so leicht zu einer Entscheidung gelangen. ${ }^{1}$ ) Zudem mußten seine Beratungen wiederholt auf längere Zeit unterbrochen werden, lind so kam es, daß sich die Reform des Eherechtes weiter hinausschob, als man anfangs hatte erwarten können.

Unterdessen ereignete sich am Hofe zu Paris ein Fall, der die Nachteile des bestehenclen Rechtszustandes für den König Heinrich II. persönlich recht linangenehm fühlbar machte. Der junge Herzog von Montmorency hatte nämlich, ohne daß sein Vater davon wußte, mit dem Hoffräulein Jeanne de Piennes durch bloße verba de praesenti eine Ehe geschlossen. Diese Ehe war aber nun gar nicht nach dem Wunsch des Vaters und noch weniger nach dem Wunsch des Königs, der den Herzog mit seiner natürlichen Tochter Diane de Farnèse hatte vermählen wollen. Man wandte sich zunächst an den Papst mit der Bitte, die noch nicht

1) Ehses-Merkle, Concilium Tridentinum I u. II, Freiburg i. Br. 1901 u. 1911, Index s. v. Matrimonium. 
vollzogene Ehe durch Dispens wieder zu lösen. Zugleich erließ König Heinrich von sich aus im Februar 1556 ein Edikt, in welchem minderjährige Personen, die ohne Genehmigung ihrer Gewalthaber eine Ehe schlossen, mit schweren Strafen, insbesondere mit Enterbung bedroht wurden. ${ }^{1}$ ) Das Edikt erhielt sogar rückwirkende Kraft für alle noch nicht vollzogenen Ehen. Diese an sich auffallende Bestimmung erklärt sich leicht aus der Rücksicht auf den besonderen Fall, dem es seine Entstehung verdankt; sie fand aber nicht den Beifall des Pariser Parlaments, welches bei der Einregistrierung neben anderen Bedingungen auch (lie bëifügte, daß es nur für künftige Ehen gelten solle. ${ }^{2}$ )

Die Gültigkeit der verbotswidrig geschlossenen Ehen wurde durch das Edikt nicht angetastet; der König achtete (len seit Jahrhunderten allgemein anerkannten Grundsatz, cla $\beta$ die Jurisdiktion über das Eheband ausschließlich der Kirche zustehe. Die Ehe des Herzogs von Montmorency freilich wurde, obwohl der Papst die erbetene Dispensation verweigerte, tatsächlich doch gelöst. Der Herzog erklärte nämlich nachträglich, er habe gar nicht die Absicht gehabt, mit dem Fräulein de Piennes eine Ehe zu schließen, habe vielmehr nur ein Eheversprech en geben wollen, und selbst dieses habe er nur zum Schein und nicht im Ernst gegeben. Die Lösung bzw. Nichterfüllung dieses in seinem rechtlichen Bestand zweifelhaft gewordenen Verlöbnisses konnte man schließlich ohne besondere Schwierigkeiten rechtfertigen.

Trotz dieser Verordnung von 1556 verfolgte die französische Regierung ihre Pläne auf dem Konzil von Trient weiter, ein Beweis dafür, daßs sie nicht beabsichtigte und sich wohl auch nicht berechtigt glaubte, aus eigener Machtvollkommenheit die Frage bezüglich der heimlichen Ehen endgültig zu lösen. Nachdem das Konzil im Jahre 1562 wieder zusammengetreten war, stellten die französischen

1) Das Edikt ist abgedruckt bei A. G. Camus, Code matrimonial I, nourelle édition, Paris 1770 , p. 99 ss. - Ich zitiere dieses sehr wichtige Werk, das anonym erschienen ist, weiterhin als "Code matrimonial" obne Angabe des Herausgebers. Verfasser des im Jahre 1766 zum erstenmal erschienentn Werkes ist Pierre Le Ridant, Advokat am Parlament von Paris. $\quad$ 2) Code matrimonial I p. 102. 
Gesandten im Auftrag Karls IX. die Doppelforderung, daß die Gültigkeit der Eheschließung allgemein von der Einhaltung einer bestimmten Form und außerdem bei gewaltunterworfenen Personen auch noch von der Zustimmung der Gewalthaber abhängig gemacht werden sollte. Die erstere Forderung wurde vom Konzil im wesentlichen erfüllt, die letztere aber wurde nach eingehender Diskussion abgelehnt. ${ }^{1}$ )

Diese Entscheidung entsprach jedoch ganz und gar nicht den Wünschen der Franzosen, die auf die Bindung der Hauskinder an die elterliche Zustimmung mehr Gewicht legten als auf die Festsetzung einer bestimmten, öffentlichen Eheschließungsform. ${ }^{2}$ ) $\mathrm{Da}$ auch verschiedene andere $\mathrm{Be}$ schlüsse des Konzils der französischen Regierung nicht genehm waren und angeblich gegen die Rechte der Krone und die Freiheiten der gallikanischen Kirche verstießen, verweigerte man trotz aller Bemühungen der Päpste und der französischen Bischöfe beharrlich die Annahme sämtlicher Disziplinardekrete desselben. ${ }^{3}$ ) Diese wurden zwar im Lauf der Zeit vielfach von einzelnen Bischöfen wie von kleineren und größeren Synoden und in den Jahren 1615 und 1625 vom französischen Gesamtklerus publiziert, so daB sie ohne Zweifel auch in Frankreich praktisch geltendes Kirchenrecht geworden sind; die staatliche Gewalt aber blieb trotzdem immer auf dem unhaltbaren Standpunkt stehen, daß die Disziplinardekrete des Tridentinums als solche in Frankreich nicht rezipiert und darum nicht verbindlich seien.

1) S. Palla vicino, Istoria del Concilio di Trento lib. XXII, cap. 1ss.; A. Theiner, Acta genuina 8. oecumenici concilii Tridentini II, Zagrabiae 1874, p. 316.

2) Doch erscheint das, was E. Friedberg, Das Reclit der Eheschließung in seiner geschichtlicher Entwicklung, Leipzig 1865, S. $505 \mathrm{f}$. hierüber sagt, als übertrieben; vgl. L. Bouchel, La Bibliothèque ou trésor du droit françois II, nouvelle édition par J. Bechefer, Paris 1671, Additions p. 20.

3) Das 1919 zu Paris erschienene Buch von V. Martin, Le Gallicanisme et la réforme catholique. Essai historique sur l'introduction en France des décrets du Concile de Trente (1563-1613), war mir leider nich $t$ zugänglich. 
Der Rapt de séduction als Ehehindernis n. gallikan. Kirchenr. $\quad 59$

\section{$\S 2$.}

Die Verordnung von Blois.

Während der lang dauernden Streitigkeiten um die Publikation der tridentinischen Reformdekrete sah sich König Heinrich III. im Jahre 1576 auf der Ständeversammlung in Blois von zwei einander entgegenstehenden Parteien gedrängt, deren eine die Publikation jener Dekrete forderte, während die andere entschieden dagegen war. Um nach Möglichkeit beiden gerecht zu werden, schlug der König einen Mittelweg ein. Er rezipierte nämlich nicht die Konzilsdekrete als solche, setzte aber doch diejenigen von ihnen, die er als den Verhältnissen seines Landes angemessen erachtete, durch königliche Verordnung auch für Frankreich in Kraft, freilich nicht ohne mancherlei Änderungen. Er tat das in der Verordnung von Blois vom Jahre 1579, die für unsere Frage von größter Bedeutung ist. In Betracht kommen hauptsächlich die Artikel 40-42.1) Artikel 40 befaßt sich mit der Eheschließungsform oder den klandestinen Ehen im eigentlichen Sinn, ist aber sehr unklar. So möchte man nach dem ersten Satz meinen, daB das Aufgebot zur Gültigkeit der Whe notwendig sei. Damit steht aber die nachfolgende Bestimmung, da $B$ die Formvorschriften dieses Artikels ,,unter den von den Konzilien festgesetzten Strafen" verpflichten, in Widerspruch; denn nie hat ein Konzil angeordnet, daß die Unterlassung des Aufgebots ein trennendes Ehehindernis bilden solle. Eine ähnliche Unklarheit besteht in bezug auf die vor.

1) Siehe Code matrimonial I p. 107. Der für unsere Frage sehr wichtige Artikel 42 sei hier wörtlich angeführt. Er lautet: Et néanmoins voulons que ceux qui se trouveront avoir suborné fils ou flle minenrs de vingt-cinq ans, sous prétexte de mariage ou autre couleur, sans le gré, sçu, vouloir et consentement exprès des pères, mères et tuteurs, soient punis de mort, sans espérance de grace et pardon, nono bstant tous consentemens que lesdits mineurs pouroient alléguer par après avoir donné audit rapt lors d'icelui ou auparavant. Et pareillement seront punis extraordinairement tous ceux qui auront participé au rapt, et qui $y$ auront prêté conseil, confort et ayde, en aucune manière que ce soit. 
geschriebene öffentliche Trauung und die dazu notwendigen Erfordernisse.

Die Praxis hat sich unter mancherlei Schwankungen, die bei der Unklarheit des Gesetzes unvermeidlich waren, im großen und ganzen an die Formvorschriften des Konzils von Trient angeschlossen und die darüber hinausgehenden Forderungen des Artikels meist als unwesentlich erklärt in dem Sinn, daß deren Außerachtlassung zwar rechtswidrig und strafbar sei, aber nicht die Lngültigkeit der Ehe bewirke. Nur bezuiglich der Aufgebote pflegte man zu sagen. daß deren Unterlassung bei Minderjährigen die Ehe ungültig mache, wenn zugleich der Konsens der Gewalthaber fehle; denn es sei der Zwerk der Aufgebote, die letzteren von der geplanten Ehe in Kenntnis zu setzen, damit sie gegebenenfalls Einspruch erheben könnten. Waren aber die Eltern mit der Verheiratung ihres Kindes einverstanden, dann war dieses nach der gewöhnlichen Meinung einem Großjährigen gleichzuachten, d. h. seine Ehe wurde durch die bloße Lnterlassung der Aufgebote nicht ungültig. ${ }^{1}$ ) Anders im umgekehrten Fall, wenn zwar die Aufgebote vorgenommen worden waren, aber der elterliche Konsens fehlte, wie sich aus den weiteren Ausführungen ergeben wird.

In den beiden Schlußsätzen des Artikels verbietet der König allen Priestern, Ehen voil minderjährigen Personen einzusegnen, wenn nicht die Genehmigung der Gewalthaber vorliegt, und zwar unter der Gefahr, als Begünstiger des rapt bestraft $z$ werden.

Artikel 41 hält die in früheren Verordnungen, insbesondere in der von 1556 festgesetzten Strafen für Eheschließung ohne elterliche Genehmigung aufrecht. ${ }^{2}$ ) Damit wäre die

1) Durand de Maillane, Dictionnaire de droit canonique et de pratique bénéficiale I, Lyon 1770, p. 265.

2) Die in Art. 41 neuerdings bestätigten früheren Verordnungen wären, da sie die Gültigkeit einer ohne elterliche Genehmigung geschlossenen Ebe nicht positiv aussprachen, sondern nur stillschweigend besteben ließen, mit einer neuen Verordnung, die deren Ungültigkeit festsetzte, nicht unvereinbar gewesen. Darum hat Art. 41 für die Interpretation der Art. 40 und 42 keineswegs die Bedeutung, die Fr. Bernard, Étude historique et critique sur le consentement des ascendants au mariage, Paris 1899, p. 125 und A. Vantroys, Etude historique et juridique 
Der Rapt de séduction als Ehehindernis n. gallikan. Kirchenr. 61

Verfehlung sicher genügend bestraft gewesen. König Heinrich aber ging nichtsdestoweniger in Artikel 42 noch viel weiter und verordnete, daß diejenigen, welche etwa durch Verführungskünste eine minderjährige Person zur Eheschließung ohne Wissen und Willen der Eltern oder Vormünder veranlaßt und sich dadurch des Verbrechens des rapt schuldig gemacht haben sollten, ohne Gnade und Erbarmen mit dem Tode zu bestrafen seien. Auch alle jene, welche ihnen durch Rat orler Tat bei ihrem Verbrechen Beistand leisteten, sollte schwerste Strafe treffen.

Die drei Artikel handeln also lediglich einerseits von der Eheschließungsform oder der klandestinen Ehe im eigentlichen Sinn und andererseits von der Eheschließung ohne elterliche Genehmigung, die oft auch als klandestine Ehe in einem weiteren Sinn bezeichnet wurde. ${ }^{1}$ ) Vom raptus violentiae ist in der Verordnung uberhaupt nicht die Rede; der wiederholt gebrauchte Ausdruck rapt bezieht sich immer nur auf die Eheschließung ohne elterliche $\mathrm{Zu}$ stimmung. Bezüglich des Artikels 40 ist das ohne weiteres klar. Eher könnte man zweifeln bei Artikel 42; allein auch hier ist nirgends von einer Gewalt die Rede, sondern nur von der Verführung, und es wird ausdrücklich der Mangel der elterlichen Genehmigung hervorgehoben. ${ }^{2}$ )

sur le consentement des parents au mariage de leurs enfants, Paris 1889, p. $251-253 \mathrm{ihm}$ zuschreiben.

1) In diesem weiteren Sinn war das Wort früher sehr gebräuchlich gewesen, aber unter dem Einfluß des tridentinischen Rechtes und der Verordnung von Blois vollzog sich eine Änderung im Sprachgebrauch, so daß nunmehr als klandestin vor allem jene Ehen bezeichnet wurden, welche ohne Pfarrer und Zeugen geschlossen worden waren. Die Behauptung von Di Pauli, Das Recht des Staates bezüglich der Aufstellung trennender Ehehindernisse nach der Lehre der französischen und deutschen Regalisten, Archiv für katholisches Kirchenrecht XCVII, 1917 , S. 45, daß in der französischen Gesetzgebung unter klandestinen Ehen, soweit nichts anderes bemerkt ist, immer die ohne Zustimmung der Eltern geschlossenen Ehen zu verstehen seien, trifft für die Zeit nach 1579 nicht mehr zu.

2) Auch zeitgenössische Autoren beziehen den Art. 42 lediglich auf die Eheschließung ohne Zustimmung der Eltern. So schreibt z. B. B. Brisson, Le Code du Roy Henry III., Paris 1609, p. 207 zu den Worten ,sans le gré, sceu etc.": D'icy se cognoist que l'ordonnance 
Ohne Zweifel bringt die Verordnung den Mangel des elterlichen Ehekonsenses in Zusammenhang mit dem Raub; dieser Zusammenhang ist nunmehr näher zu bestimmen.

Nach Artikel 40 ist es den Geistlichen verboten, die von den Eltern nicht genehmigten Ehen minderjähriger Kinder einzusegnen, und sie sollen im Fall der Zuwiderhandlung als Begünstiger des Raubes strafbar sein. Diese Strafdrohung ist neu. Nichts Neues aber war es, da $B$ man von rapt redete, wo bloß Eheschließung ohne Genehmigung der Eltern vorlag. Die ganze Bestimmung bildete ja lediglich die Antwort des Gesetzgebers auf einen Antrag, den die Vertreter des dritten Standes auf der Versammlung von Blois im Jahre 1576 gestellt hatten, ,qu' il fût interdit aux curés de passer outre à la célébration des mariages, $s^{\prime}$ il ne leur apparaît du consentement des père, mère et curateur .... sous peine d'être punis comme fauteurs

ne parle point du rapt faict par force, violence, et enlevement de filles, lequel est puny selon les rigueurs des loix, au tiltre ad leg. Iul. D. de vi publ. l. un. C. de raptu virg. vidu. et sanctim. Mais que ladite ordonnance s'entend seulement du rapt fait par persuasion, induction, et subornation, sous pretexte et couleur de mariage, pour servir de voile et excuse su delict ... . De façon que tel rapt peut estre ainsi appellé eu esgard aux parens ou tuteurs qui n'ont presté leur consentement, et tout ce qui se faict outre leur gré et consentement doibt estre estimé fait par force, encores que les filles mineurs l'ayent pour agreable, suivant la loy nuptiae $D$. de nuptiis: nuptiae consistere non possunt nisi consentiant omnes i. e. qui coeunt, quorumque in potestate sunt; combien que le droict canon en ait autrement décidé, neantmoins les loix civiles ont esté plustost suivies en ce point, et semblent y apporter plus de respect pour ce qui concerne l'honnesteté publique: d'ailleurs aisement les filles se laisseroient tromper si elles n'estoient assistees de conseil, et la persuasion serviroit de rapt pour faire consentir par force celle de laquelle le consentement seul n'est capable, en laquelle persuasion se peut dire aussi qu'il y a de la force, voire qui contrainct plus que la force mesme. An der gleichen Stelle sagt Brisson später noch: Co qui est du rapt des filles s'entend e converso des fils de famille ou mineurs seduits par des femmes aagees, outre le gré de leurs parens et tuteurs: ce qui a esté jugé par plusieurs arrests. - Dieselbe Auffassung vertritt A. Théveneau, Commentaire sur les Ordonnances, Lyon 1648, p. 267 : Cette Ordonnance ne parle pas du rapt et enlevement par voye de fait, ains seulement de la subornation des mineurs de 25 ans. 
du crime de rapt". ${ }^{1)}$ Ferner bezeugt uns Pasquier, daß man in Frankreich schon früher bei Eheschließung mit Kindern unter 25 Jahren ohne Genehmigung der Eltern diesen auf Grund älterer Gesetze immer eine Klage wegen rapt gab ${ }^{2}$ ), und ebenso kennt Gu y Coquille einen rapt, der einzig und allein auf der Umgehung der elterlichen Autorität bei der Eheschließung mit einem Hauskinde, gleichviel ob Tochter oder Sohn, beruhte. ${ }^{3}$ )

Allein dieser rapt war kein Ehehindernis; er konnte vor dem kirchlichen Gericht, das über das Eheband zu entscheiden hatte, uiberhaupt nicht geltend gemacht werden. Er war lediglich ein Verstoß gegen ein weltliches Gesetz und wurde als solcher von den weltlichen Gerichten mit manchmal ziemlich empfindlichen Strafen, Geldstrafen, Verbannung $u$. dgl. belegt, nicht aber mit der Todesstrafe, welche man bei gewaltsamer Entführung zu verhängen pflegte, und welche Pasquier auch für jene anderen Fälle von rapt verlangte.")

Eine Neuerung hinsichtlich der Behandlung dieses rapt enthielt Artikel 40 in so fern, als er verfügte, daB bei Eheschließung gewaltunterworfener Personen ohne Genehmigung

1) Zitiert bei L. Duguit, Etude historique sur le rapt de séduction, Nouvelle Revue historique de droit français et étranger X, 1886, p. 618.

2) In einem Brief an die Professoren Robert und Fournier schreibt er folgendes (Lettres, livre III, 1): Nos ancestres cognoissans combien c'estoit chose de mauvais exemple, qu'un enfant au dessous de 25 ans fust estimé marié par les paroles de present au prejudice de l'authorité paternelle, introduisirent l'action de Rapt (que nous appellons vulgairement Paptum in parentes) qui est incogneuë à toutes autres nations; par laquelle on permettoit aux peres et meres, voire aux tuteurs, d'accuser devant le Juge Royal celuy ou celle qui par telle affeterie de paroles auroit attiré et suborné à un mariage, l'un de leurs enfans. - Vgl. dazu die beiden Urteile des Pariser Parlaments vom 3. Juni 1535 und rom 26. März 1554 (Code matrimonial II p. 872s.).

3) Les Oeuvres de maistre Guy Coquille I, Bordeaux 1703, p. 477 : La loy repute que la fille est ravie quand par blandices, et allechemens sa volonté est gagnée. L'autre sorte de rapt est qu'on ravit et ôte aux pere, mere et tuteurs, soit paternels ou maternels, l'authorité, conseil et commandement qu'ils ont sur les mineurs en affaire de si grande inportance.

4) In dem oben Anm. 2 erwähnten Briefe. 
der Gewalthaber fürderhin auch der trauende Priester strafbar sein sollte. Auf diese Weise war eine neue Sicherung für die Beobachtung des alten Verbots derartiger Ehen geschaffen, aber an der bisherigen Gültigkeit derselben wurde durch Artikel 40 nichts geändert. ${ }^{1}$ )

Eine ganz andere Sachlage dagegen ergab sich, wenn die Umgehung der elterlichen Autorität bei der EheschlieBung nicht auf den freien Willen des Minderjährigen, sondern auf eine Verführung desselben durch eine dritte Person, vor allem durch den großjährigen Brautteil zuriickging. Auch in diesem Fall lag natürlich rapt vor; dieser rapt aber hat in bezug auf die Gültigkeit der Ehe eine wesentlich andere Wirkung als der rapt, von dem in Artikel 40 die Rede ist.

Für die Bewertung des raptus als Ehehindernis war nach französischem Recht bis zur Verordnung von Blois, ausschließlich das auch vom Staat anerkannte vortridentinische Kirchenrecht maßgebend. ${ }^{2}$ ) Nach diesem bildete er nur dann ein trennendes Ehehindernis, wenn wirklich die notwendige Konsensfreiheit der Entführten ausgeschlossen war. Das war ohne $Z$ weifel der Fall bei der Anwendung physischer Gewalt von seiten des Entführers; da rüber konnte es nie eine Meinungsverschiedenheit geben. Wie aber, wenn nicht physische Gewalt, sondern nur die Mittel der Überredung und Verführung angewendet wurden? Das Dekretalenrecht hatte diesen letzteren, wie Gratian, keine oder doch nur geringe Bedeutung beigelegt im Unterschied vom römischen Recht, das bei Zustimmung des Weibes zur Entführung immer Verführung durch den Mann vermutete und die Verführung in ihrer Wirkung auf den Willen der Verführten der Gewalt gleichstellte. Heinrich III. greift nun

1) Das gilt aber nur von Art. 40, nicht auch von Art. 42, wie sicb aus dem im Text Folgenden ergibt.

2) Das römisch-rechtliche Ehehindernis des raptus (1. un. C. IX, 13) war unter dem Einfluß des kanonischen Rechtes längst außer Geltung gekommen und wurde auch durch die Verordnung von Blois nicht wieder erneuert. Das tridentinische impedimentum raptus aber war damals in Frankreich rom Staat noch nicht rezipiert und wurde es auch nicht durch die Verordnung ron Blois. 
hierin wieder auf die Anschauungen des römischen Rechtes zurück und nicht nur das, sondern er geht sogar, sei es mit bewußter Absicht, sei es in mißverständlicher Auffassung, über das römische Recht weit hinaus, indem er das, was das letztere nur von der Zustimmung eines Mädchens zu einer wirklichen Entführung, d. h. Wegführung aus dem Vaterhaus an einen anderen Ort, gesagt hatte. übertrug auf die einfache Eheschließung gewaltunterworfener Personen, gleichviel ob Sohn oder Tochter, ohne Genehmigung der Gewalthaber. Er sagt freilich nicht direkt, daß bei jeder Eheschließung ohne den Willen der Eltern rapt infolge Verführung anzunehmen sei; aber er gibt zu erkennen, daß ein Hauptmerkmal der Verführung zu finden sei in dem Mangel des elterlichen Konsenses, während von wirklichen Mitteln oder Künsten der Verführung gar keine Rede ist. 1) Er sagt ferner auch nicht ausdrücklich, daß die Verführung die Freiheit des Ehekonsenses ausschließe und infolgedessen die Ungültigkeit der Ehe bewirke; aber er belegt denjenigen, der eine minderjährige Person zur Eheschließung ohne Genehmigung der Eltern veranlaßt, mit der zivilrechtlichen Strafe des raptus, d. h. mit der Todesstrafe, und ordnet weiter an, daß auf die Zustimmung, die die Verführte vor dem rapt oder bei demselben gegeben hat, keinerlei Rücksicht zu nehmen sei. Die Todesstrafe hatte man bisher nur in Fällen wirklicher Entführung ausgesprochen. Wenn der König jetzt die nämliche Strafe über bloße Verführung zur Eheschließung ohne Genehmigung der Eltern verhängt, so zeigt er damit, daß er dieselbe jenem schweren Verbrechen gleichstellt. ${ }^{2}$ ) Nach der gleichen

1) Die Ansicht, daB der Mangel des elterlichen Konsenses in Art. 42 deshalb hervorgehoben werde, weil er den sicheren Schluß auf das Vorliegen einer Verführung gestattet, vertritt auch Brisson (vgl die oben S. $61^{3}$ angeführte Stelle). Ebenso erklärt Tbéreneau, daß die Verordnung sich hinsichtlich der Frage, ob der bloße Mangel des elterlichen Ehekonsenses raptus begründe, nicht dem kanonischen, sondern dem Zivilrecht angeschlossen habe (p. 533: Toutefois par l'Ordonnance qui s'accorde en cecy avec le Droict Civil, il y auroit rapt).

2) Vgl. A. Théveneau p. 267: Cette Ordonnance ne parle pas du rapt et enlevement par voye de fait, ains seulement de la subornation des mineurs de 25 ans; et pourtant elle establit une pareille peine, pource 
Richtung weist die Anordnung, daß auf die Zustimmung der verführten minderjührigen Person keine Rücksicht zu nebmen sei; denn der Grund dieser Anordnung liegt offenbar darin, daß nach der Meinung des Gesetzgebers die Zustimmung einer verführten Person wesentlich durch die List und Künste des Verführers veranlaßt, also nicht frei gegeben ist. ${ }^{1}$ )

Die Ungültigkeit der Ehe ergab sich daraus von selbst, solange noch der Satz galt, daß eine Ehe nur durch den freien Konsens der Kontrahenten zustande kommen könne. ${ }^{2}$ ) Von dieser Erwägung hatte sich wohl auch das Pariser Parlament leiten lassen, als es durch Urteil vom 17. Februar 1544 aussprach, daß der kirchliche Richter einen Prozeß über das Eheband nicht mehr einleiten oder weiterführen dürfe, wenn der rapt offenbar als erwiesen und todeswürdig anzusehen sei. ${ }^{\text {) }}$

qu'il n'y a point de difference . . . entre l'estre forcé par voye de fait, et induit par subornation.

1) $\mathrm{DaB}$ diese Anordnung im oben angegebenen Sinn gedeutet wurde, zeigen uns wiederum Brisson und Théveneau. Brisson stellt die Überredung der Gewalt nicht nur gleich, sondern sogar noch über dieselbe (siehe oben S. 61 ${ }^{2}$ ) und ähnlich bemerkt Théveneau p. 534: L'Ordonnance n'a point d'esgard à toutes ces distinctions (nämlich ob die Minderjährige der Entführung zustimmte oder nicht), et repute le consentement de la fille nul, pource qu'elle presume avec la loy I. Cod. de raptu virg. qu'elle a esté deceuë et circonvenuë.

2) Siehe Claude Blondea u, La Bibliothèque canonique II, Paris 1689 , p. 80: La seconde est (nämlich die 2 weite Art, wie ein weltliches Gericht über das Eheband entscheiden kann), lors qu'en procedant à la punition d'un crime, comme celuy du rapt, qui a donné lieu au mariage, on declare qu'il y a rapt. Car en ce cas là, quand mesme on ne prononceroit pas sur la validité du mariage, il s'ensuivroit necessairement qu'il seroit aneanty; parce que la declaration du rapt emporte celle de la nullité du mariage. Ebenso nochmal ganz klar und deutlich p. 82. - Die erste Auflage dieses reichbaltigen Werkes, herausgegeben im $\mathrm{Jahr} 1628$ von Laurent Bouchel unter dem Titel Somme bénéficiale, konnte ich leider in einer deutschen Bibliothek nicht ausfindig machen; sie würde wohl interessantes Material für die Geschichte des rapt de séduction bieten. - Die nämliche Ansicht wie Blondeau vertritt Durand de Maillane III p. 283.

3) Vgl. J. Paponius, Corpus Juris Francici seu Absolutissima Collectio Arrestorum, Coloniae Allobrogum 1624, lib. XXII, tit. VI, arr. 2. 
Dafür, daß diese zum Teil nicht gerade klar und deutlich ausgesprochenen Gedanken nicht unbeachtet bleiben, sondern in die Praxis umgesetzt würden, bürgten dem König zwei Umstände, nämlich einmal die Auffassung der Juristen, welche die Eheschließung der Hauskinder ohne Genehmigung der Eltern verabscheuten und sich schon längst geneigt zeigten, dieselbe als durch Verfuihrung veranlaßt und darum als unfrei und ungültig anzusehen ${ }^{1}$ ); ferner die Tatsache, daß die von den Juristen beherrschten Parlamente, wie eben bemerkt, schon einige Jahrzehnte früher begonnen hatten, unter Zurückdrängung der kirchlichen Gerichte die Rechtsprechung über jene Ehefälle, bei welchen raptus in Frage kam, an sich zu ziehen, womit den Juristen die Möglichkeit gegeben war, den Gedanken der Ordonnanz, die mit ihren eigenen so gut harmonierten, tatsächlich Geltung zu verschaffen.

Das Ergebnis unserer Untersuchung über die Verordnung von Blois ist also folgendes:

Die ohne elterliche Genehmigung geschlossenen Ehen der Kinder werden nicht wegen dieses Mangels als solchen für ungültig erklärt; wohl aber gibt der König dem Begriff des schweren, ehehindernden Raubes eine derartige Ausdehnung, daB jene Ehen leicht darunter gebracht werden können. Einerseits nämlich erklärt er, daß auch durch bloße Verführung zur Eheschließung ohne Konsens der Eltern ein schwerer Raub begangen werde, und andererseits stellt er, wenn auch nicht mit dürren, klaren Worten, eine Rechtsvermutung dafür auf, da $B$ bei Mangel der elterlichen Genehmigung Verführung vorliege. Daß diese Rechtsvermutung als unwiderleglich anzusehen sei, ist nicht gesagt. Sie konnte aber in der Praxis leicht dazu werden, da der Mangel des Elternkonsenses, also eine in den fraglichen Fällen notwendig gegebene Tatsache, als Merkmal der Ver-

- Vielleicht war anfänglich auch nur der Gedanke maßgebend, daB das Urteil des kirchlichen Richters überflüssig sei, da auch eine wirklich bostehende Ehe durch die Vollstreckung des Todesurteils alsbald aufgelöst würde und ihre bürgerlichen Wirkungen durch das Urteil des weltlichen Gerichtes für jeden Fall völlig aufgehoben wurden.

1) Vgl. die oben S. $63^{2}$ angeführte Äußerung von Pasquier. 
führung in den Vordergrund gestellt, die freie Zustimmung des Minderjährigen dagegen, die den wichtigsten Gegenbeweis bilden mußte, als völlig unbeachtlich erklärt ist.

Alles in allem haben wir in den Artikeln 40 und 42 unserer Verordnung eine Norm, bei der sehr viel darauf ankam, wie sich die Praxis zu ihr stellte.

$\S 3$.

Die Verordnung von 1629.

Die nächste für unseren Gegenstand bedeutsame Verordnung ist jene Ludwigs XIII. von 1629; von ihr kommen die beiden Artikel 39 und besonders 169 in Betracht. ${ }^{1}$ )

Was zunächst den Artikel 39 betrifft, so streiten die Gelehrten über seine Tragweite. Die einen sind der Ansicht, daß durch denselben alle Ehen, welche in der Ordonnanz von Blois verboten sind, für ungültig erklärt werden sollen; andere dagegen wollen ihn nur auf die klandestinen Ehen im eigentlichen Sinne beziehen, nicht aber auf die Raubehen, noch weniger auf die Ehen, welche zwar ohne Genehmigung der Eltern, sonst aber unter Einhaltung der vorgeschriebenen Form geschlossen wurden. Ich schließe mich der letzteren Auffassung an, da der Artikel die Verordnung von Blois nicht in ihrem ganzen Umfang ins Auge faßt, sondern nur in so weit, als sie sich gegen die klandestinen Ehen wendet. ${ }^{2}$ ) Mit den klandestinen Ehen aber, welche in jener Verordnung genannt und für ungültig erklärt werden, sind nicht die Ehen gemeint, welchen lediglich die elterliche Genehmigung fehlt, sondern nur die klandestinen Ehen im eigentlichen Sinn. ${ }^{3}$ )

1) Den Text siehe im Code matrimonial I p. 113 ss.

2) Der Artikel beginnt mit den Worten: L'ordonnance de Blois, touchant les mariages clandestins, sera exactement observée.

3) Art. 40 der Verordnung von Blois, der sich gegen die klandestinen Ehen wendet, ist ganz allgemein gehalten; seine Formvorschriften gelten für die Ehescbließung aller Untertanen des Königs (,que nos sujets, de quelque état, qualité et condition qu'ils soient, ne pouront valablement contracter mariage ${ }^{6)}$. 
Der französische Klerus erhob gegen diesen Artikel $\checkmark$ orstellungen beim König und verlangte zweierlei, nämlich :

1. eine ausdrückliche Erklärung, daB die Worte ,,valablement ou non valablement contracte", die sich im angeführten Artikel der Verordnung von Blois finden, nur auf den bürgerlichen und nicht auf den geistlichen Vertrag bezogen werden dürften, und

2. daß der letzte Satz des Artikels 39, der die kirchlichen Richter an eine staatliche Verordnung band, weggelassen werde, da dieselben einzig und allein die Dekrete und Konstitutionen der Kirche zur Richtschnur nehmen könnten.1)

Beiden Forderungen wurde in der Antwort des Königs stattgegeben; allein dieses Entgegenkommen bedeutete praktisch sehr wenig. Bezüglich des ersteren Punktes werde ich diese Behauptung im folgenden Paragraphen zu beweisen suchen; bezüglich des letzteren braucht man sich nur daran zu erinnern, daß über den kirchlichen Ehegerichten immer das Damoklesschwert des appel comme d'abus schwebte, von dem häufig und sehr oft mit Erfolg Gebrauch gemacht wurde. In diesen Fällen urteilten in letzter Instanz die Parlamente, die ihren Entscheidungen vor allem die königlichen Verordnungen wie überhaupt das in erster Linie maßgebende französische Sonderrecht zugrunde legten und auch darüber zu befinden hatten, wie die kirchlichen Kanones auszulegen und anzuwenden seien.

Artikel 169 handelt vom rapt, will aber darunter allem Anschein nach nicht nur die eigentliche Entführung verstehen, sondern auch die Eheschließung ohne elterliche Genehmigung, ohne das indes mit voller Klarheit und Unzweideutigkeit auszusprechen. Als Beweggründe für sein Vorgehen gegen den rapt führt der Gesetzgeber an die Erhaltung der elterlichen Autorität über die Kinder, die Ehre und Freiheit der Ehen, die Ehrfurcht, die einem so

1) Die Eingabe des Klerus und die Antwort des Königs finden sich in Recueil des actes, titres et mémoires concernant les affaires du Clergé de France V, Paris 1716, col 6928. (ich zitiere dieses Werk fortan als „Mémoires du Clergéc); vgl. Code matrimonial I p: $113^{b}$. 
heiligen Sakrament gebührt ${ }^{1}$ ) und die Verhinderung von Mißheiraten, die so häufig Unfrieden in den besten und vornehmsten Familien des Landes verursachten. Schon dadurch zeigt er, daB es ihm wenigstens ebensosehr, wenn nicht mehr um die Wahrung der elterlichen Rechte über die Ehen der Kinder als um den Schutz der Eheschließungsfreiheit der Kinder selbst zu tun war.

Er erneuert dann zunächst die früheren Verordnungen über die Bestrafung des rapt und bestimmt weiter, daß die über die Entführer und deren Helfer verhängten Strafen nicbt nur jene treffen sollen, welche sich einer eigentlichen Entführung von gewaltunterworfenen Personen schuldig gemacht haben, sondern auch jene, welche minderjährige Personen dazu verführt haben, sich ohne Zustimmung ihrer Gewalthaber zu verehelichen. Ob eine solche Verführung immer anzunehmen sei, wenn die elterliche Genehmigung zur Eheschließung fehlt, wird nicht ausdrücklich gesagt; für die bejahende Antwort spricht aber meines Erachtens der Umstand, daß sonst nirgends mehr in unserer Verordnung von der so sehr verpönten Eheschließung ohne Konsens der Eltern und deren Bestrafung die Rede, ist und ferner besonders die Tatsache, daß die Rechtsprechung schon damals bei solchen Ehen regelmäßig Verführung des minderjährigen Teiles annahm und auf Grund dieser Annahme die Ehen wegen rapt für ungültig erklärte. Die Strafen der Entführer und ihrer Helfer und Begünstiger sind von einer kaum mehr zu überbietenden Strenge; jedes gerechte und vernünftige Maß scheint der Gesetzgeber verloren zu haben.

Schließlich werden die genannten Verbrechen, die eigentliche Entführung und die ,,Verführung“ mit den Be-

1) Die Hervorhebung dieser Zwecke nötigt durchaus nicht, ausschließlich oder vorzugsweise an den raptus riolentiae zu denken, da nach französischer Auffassung die Ehre und die Freiheit der Ehen und die dem Sakrament gebührende Ehrfurcht durch ,Verführung“ Minderjühriger mindestens ebensosehr beeinträchtigt wurden als durch physiscie Gewalt. Vgl. z. B. die Ausführungen des Staatsanwalts Bignon im ProzeB Danfernel-Larchevêque im Jahr 1632 bei Pierre Bardet, Recujil d'Arrests du Parlement de Paris II, Paris 1690, liv. 1, ch. 6. 
Der Rapt de séduction als Ehehindernis n. gallikan. Kirchenr. 71

zeichnungen ,telles entreprises" und "tels crimes" zusammengefaßt, und der König erklärt, Maßnahmen treffen zu wollen, welche ihnen für die Zukunft ein Ende machen würden. $Z u$ diesem $Z$ weck verordnet er, daß Ehen, die zwischen den entführten Personen und ihren Entführern geschlossen worden sind, als gänzlich ungültig und wirkungslos gelten sollen, ,gemäß den heiligen Dekreten und den kanonischen Bestimmungen". Sie sollen auch durch nachträgliche Zustimmung der entführten Personen und ibrer Gewalthaber in keinem Fall mehr gültig gemacht werden können.

Die Verordnung steht, wie man ohne weiteres sieht, mit dem tridentinischen Recht in schroffem Widerspruch und schließt sich eng an das römische Recht Justinians an. In der Praxis wurde sie indes kaum jemals angewendet, da die Parlamente aus Gründen, die uns nicht mehr bekannt sind, trotz aller Bemühungen des Königs beharrlich ihre Einregistrierung verweigerten.

\section{$\S 4$.}

Die Eheangelegenheit des Herzogs von Orléans.

In den dreißiger Jahren des 17. Jahrhunderts wirbelte die Eheangelegenheit des Herzogs Gaston von Orléans in den höchsten Gesellschaftskreisen Frankreichs viel Staub auf. $\left.{ }^{1}\right)$ Der Verlauf dieser Angelegenheit ist für uns sehr wichtig und lehrreich, da die Prinzen des königlichen Hauses gegenüber dem Träger der Krone in manchen Punkten und besonders hinsichtlich der Eheschließung ungefähr in dem nämlichen Abhängigkeitsverhältnis standen wie die Kinder gegenüber ihren Eltern und die Mündel gegenüber ihren Vormündern.

Gaston, der einzige Bruder des damals noch kinderlosen Königs Ludwig XIII., vermählte sich nach dem friihen Tode seiner ersten Gemahlin Maria von Montpensier

1) Ein eingehender Bericht über diese Angelegenheit findet sich im Code matrimonial II p. 786ss.; siehe auch Mémoires du Clergé $V$ col. $693 \mathrm{ss}$. 
im Jahre 1632 mit der Prinzessin Margareta, einer Schwester des Herzogs Karl von Lothringen, obwohl der König wiederholt erklärt hatte, daß er diese Verbindung unter keinen Umständen dulden könne und wolle. Ludwig war auch gegenüber der vollendeten Tatsache keineswegs zur Nachgiebigkeit geneigt, tat vielmehr, sobald er von dem AbschluB der zunächst geheim gehaltenen Ehe sichere Kenntnis erlangt hatte, sofort Schritte, um sie für ungültig erklären zu lassen. Richelieu erzählt uns in seinen Memoiren ${ }^{1}$ ), wie man hin und her beriet, ob man die Nichtigkeitsklage vor dem weltlichen Gericht, dem Pariser Parlament, oder vor dem kirchlichen Gericht anstrengen solle. SchlieBlich erklärte der König seinen Willen dahin, die Sache vor das kirchliche Gericht zu bringen unter der Bedingung, daß der Papst durch französische Richter in Frankreich die Entscheidung fällen lasse. Papst Urban VIII. aber, der recht wohl erkannte, daß es dem französischen Hof nur darum zu tun war, um jeden Preis ein Nichtigkeitsurteil zu erlangen, ging mit Recht auf diese Bedingung nicht ein, weshalb der König ,,aus Furcht, daß man in Rom die französischen Gesetze nicht genügend kenne ${ }^{2}$ ), und daß sich die Angelegenheit $z u$ sehr in dic Länge ziehen würde, sich entschloB, sofort vor seinem Parlament die Klage wegen raptus anzustrengen". ${ }^{3}$ ) Er tat das am 2. Januar 1634, und am 5. September desselben Jahres erklärte das Parlament die Ehe wegen raptus als non valablement contracté.

Einige Männer, die mit diesem Urteil nicht einverstanden waren, wandten sich nun an den päpstlichen Nuntius und stellten ihm vor, daß dasselbe einen Übergriff der weltp. 6388 .

1) M. Petitot, Collection des Mémoires XXVIII, Paris 1823,

2) Der Papst hatte den Gesandten Ludwigs klar und bestimmt den Bescheid gegeben: Galliae speciales leges nulla vi pollere in sacra. mentum quod a Christo institutore et Ecclesiae canonibus unice pendebat. Qualescumque essent civiles harum legum effectus, persistere immotum. que esse connubii vinculum (E.Valton in Vacant-Mangenot, Dictionnaire de théologie catholique IV/2, Paris 1911, col. 2450).

8) Petitot p. 65. 
lichen Gewalt in die Rechte der kirchlichen Autorität bedeute. Daraufhin wandten sich die Minister des Königs mit Gegenvorstellungen ebenfalls an den Nuntius und erklärten ihm vor allem, daß das Urteil ,non valablement contracté sich lediglich auf den bürgerlichen Vertrag beziehe und in keiner Weise die Ehe als Sakrament berühre; dies ergebe sich schon aus dem Wortlaut, da die Parlamente, wenn sie einer Ehe die Gültigkeit absprechen wollen, dieselbe als ,non valablement contractéc" erklären, während die kirchlichen Gerichte, die über den Bestand des Sakramentes urteilen, sie als ,"nul“" bezeichnen. ${ }^{1}$ )

Diese beschwichtigende Erklärung der französischen Regierung darf indes ebenso wie die bereits erwähnte, ähnlich lautende Antwort Ludwigs XIII. auf die Beschwerden des Klerus über die Verordnung von 1629 nur im Zusammenhang mit den damals in Frankreich herrschenden Anschauungen über den contrat civil und dessen Vërhältnis zum Sakrament der Ehe gewertet werden; in diesem Zusammenhang aber hat sie meines Erachtens doch einen ganz anderen Sinn als den, in dem der Nuntius sie nach dem Willen der Minister verstehen sollte, und den man zumächst tatsächlich aus ihr herauslesen möchte. In jener Zeit huldigten nämlich nicht nur die allermeisten französischen Juristen, sondern auch nicht wenige französische Theologen bereits der Ansicht, daß der. bürgerliche Ehevertrag die Grundlage und Voraussetzung des Ehesakramentes als dessen Materie bilde ${ }^{2}$ ),

1) Petitot p. 74.

2) Für die Juristen bedarf die Behauptung kaum eines Beweises. Fïr die Theologen verweise ich auf Hennequin, der damals (seit 1607) Professor an der Sorbonne war und das gröBte Ansehen genoB (siehe darüber den Ausspruch Pithous bei M. Covillard, Le mariage consideré comme contrat civil dans l'histoire du droit français, Paris 1899 , p. 39) und auf Bischof Fenoillet von Montpellier, den Präsidenten der Generalversammlung des Klerus von 1635. Hennequin äußert sich darüber (nach Jacques Boileau, Traité des empêchemens du mariage in Ioannis Launoii Opera omnia IV, P. II, Coloniae Allobrogun 1731, p. 318): . . Christus Matrimonium instituendo Sacramentum, nihil in illo ut contractu civili immutavit, sed tantum illi ut praerequisito fundamento necessario imposuit, trunco inseruit, principali anuexuit, materiali affixit naturam et dignitatem Sacramenti, ita ut 
daß derselbe aber nichtsdestoweniger nach wie vor der Jurisdiktion der weltlichen Gewalt unterstehe; demnach sei es Sache des Staates, die Bedingungen festzusetzen, unter denen ein gültiger Vertrag und damit die Materie des Sakramentes zustande kommen kann, und ebenso sei es Sache des Staates, in zweifelhaften Fällen darüber zu entscheiden, ob ein bereits geschlossener Vertrag gültig war oder nicht. Lautete die Entscheidung auf Ungültigkeit des Vertrages, so war damit die Ungültigkeit des Sakramentes von selbst gegeben, weil dieses eben ohne einen gültigen bürgerlichen Ehevertrag gar nicht existieren kann.

Daß man in den maßgebenden Kreisen Frankreichs damals die Dinge tatsächlich so auffaßte, ergibt sich aus folgenden Gründen:

1. Nicht nur die meisten Juristen, sondern auch viele Theologen gestanden den weltlichen Fürsten das Recht zu. trennende Ehehindernisse aufzustellen, und dabei dachte man durchweg an Hindernisse, welche nicht nur die bürgerliche Geltung der Ehe hinderten, sondern überhaupt gar keine Ehe zustande kommen ließen, so daß natürlich auch vom Ehesakrament keine Rede sein konnte. Dieses Recht der Fürsten, trennende Ehehindernisse aufzustellen und damit auch das Zustandekommen des Sakramentes zu hindern, beruhte aber einzig und allein auf ihrer Jurisdiktion über den bürgerlichen Vertrag, der die Materie des Sakramentes bildet; die Jurisdiktion über das Sakrament als solches steht nur der Kirche zu. ${ }^{1}$ )

matrimonium contractum civilem reliquerit huiusmodi post, cuiusmodi erat ante sui institutionem et elevationem in Sacramentum. - Fenoillet sagt in seiner Rede an den versammelten Klerus geradezu: Sa matière (nämlich des Fhesakramentes) c'est le consentement des deux parties, marqué dans le contrat civil (Code matrimonial II p. 798) und später: Le contrat civil n'est contrat que par l'autorité que lui donne le prince séculier (ibid. p. 800).

1) Ich verweise auch hier für die Theologen wieder auf Hennequin und Fenoillet. Ersterer schreibt (an der eben angefibrten Stelle): Et certe cum ex omnium consensu Principes politici Matrimonium baptizatorum Sacramentum quatenus contractum civilem possint impedire ne contrahatur licite, seu sub poena tam corporali exempli causa mortis, quam spirituali, exempli causa, peccati, proindeque privationis gratiae 
2. Schon in der zweiten Hälfte des 16. und zu Beginn des 17. Jahrhunderts hatte sich der französische Klerus lebhaft darüber beklagt, daß die Laienrichter in Ehesachen so häufig auf das Rechtsgebiet der Kirche übergriffen. Ohne Zweifel handelte es sich bei diesen Klagen um die Rechtsprechung über das Eheband; denn eine Jurisdiktion über die bürgerliche Anerkennung und die bürgerlichen Folgen der Ehe hätte die französische Geistlichkeit damals sicher nicht mehr beansprucht, und wenn sie es getan hätte, dann hätte sie ganz gewiß auf eine Unterstiutzung ihres Anspruchs durch den König in keiner Weise rechnen dürfen. Wenn nun dennoch die Könige Heinrich III. und Heinrich IV. in ihren Verordnungen von 1580 und 1606 den Beschwerden des Klerus wenigstens zum Teil stattgegeben haben ${ }^{1}$ ), so ist das ein sicherer Beweis, daß die Parlamente sich schon damals die Rechtsprechung über das Eheband selbst an-

Matrimonio Sacramento propriae, adhibendo impedimenta prohibentia; etiam poterunt impedire, ne contrahatur valide sub poens nullitatis adhibendo impedimenta dirimentia: Cum tam prohibitio quam diremptio Matrimonii baptizatorum Sacramenti in suo ordine saltem mediate et indirecte Matrimonium Sacramentum respiciat et attingat. Die weltlichen Fürsten können also trennende Ehehindernisse aufstellen, indem sie den Ehevertrag, über den sie Gewalt haben, direkt und damit indirekt auch das Sakrament, welches den Vertrag voraussetzt, irritieren. Boileau versichert überdies noch ausdrücklich (ibid.॰p. 319), Hennequin habe ihm wie vielen anderen unzählige Male gesagt, daB nach seiner Ansicht die Könige für die Ehen ihrer Untertanen trennende Hindernisse aufstellen könnten. - Noch ausführlicher als Hennequin äuBert sich Bischof Fenoillet in seiner schon angeführten Rede (Code matrimonial II p. 798 ss.) über das unveräußerliche Recht der Fürsten zur Aufstellung trennender Ehehindernisse. Diese beiden Männer standen aber mit ihren Ansichten im französischen Klerus keineswegs allein. Hennequin beruft sich ja in der obigen Stelle selbst auf den ",consensus omnium" und hätte seine Lehre sicherlich nicht jahre- und jahrzehntelang unangefochten an der Sorbonne vortragen können, wenn nicht wenigstens ein großer Teil seiner Kollegen mit ihm darüber einig gewesen wäre (vgl. auch Boileau p. 335). Ebensowenig trug Fenoillet nur seine persönliche Meinung vor, sondern die Iehre, die er und seine Mitarbeiter beim Studium der einschlägigen Literatur und in Besprechungen mit den bedeutendsten Pariser Theologen als die meist vertretene und am besten begründete erfunden hatten.

1) Siehe unten $\S 6$. 
maßten und sich nicht mit der Rechtsprechung über die bürgerlichen Wirkungen der Ehe begnügten.

Nun hat Ludwig XIII. allerdings später auch noch eine Entscheidung der französischen Bischöfe über die Gültigkeit der Ehe seines Bruders herbeigeführt. Wie kam er dazu, nochmals das Urteil der Bischöfe anzurufen, wenn für ihn ohnehin schon auf Grund des Parlamentsurteiles feststand, daß die Ehe auch dem Bande nach nichtig war?

Die Sache ist m. E. nicht allzu schwer zu erklären. Der Herzog von Orléans weigerte sich nämlich trotz allen Zuredens beharrlich, seine Ehe mit Margareta auf Grund des Parlamentsurteils als ungültig anzusehen, und berief sich fortwährend darauf, daß sein Gewissen ihm verbiete, sich dem Urteil zu unterwerfen, da über Gültigkeit und Ungültigkeit der Ehe nur die Kirche, ja nur der Papst selbst entscheiden könne. Nun aber konnte man den Bruder des Königs und mutmaßlichen Thronfolger doch nicht gut wie einen beliebigen Bürger behandeln und ihn rücksichtslos durch Gewalt zur Nachgiebigkeit zwingen, sondern mußte seinen Einwendungen wohl oder übel in etwa Rechnung tragen. Ebenso mußte man, zumal bei der hervorragenden Stellung der beteiligten Personen, auf die öffentliche Meinung einige Rücksicht nehmen; denn vom Ausland ganz abgesehen, waren auch in Frankreich selbst nicht einmal die eifrigsten Verfechter der königlichen Befugnisse über die Ehe durchweg davon überzeugt, daß die Ehe des Herzogs wirklich ungültig war. $\left.{ }^{1}\right)$ Infolgedessen mußte es dem König naturgemäß sehr erwünscht sein, das Urteil des Parlamentes durch ein kirchliches Urteil bestätigt zu sehen, und darum beschloß er, die Sache der im Jahre 1635 zusammentretenden Generalversammlung des Klerus vorzulegen.

Dafür, daß diese Erklärung das Richtige trifft, spricht auch der Umstand, daß der König erst im Juni des Jahres 1635 sich an die Bischöfe wandte, während er die Klage vor dem Parlament bereits im Januar 1634 erhoben hatte.

1) So hielt, wie es heißt, Hennequin die Ehe für gültig, weil der König von seinem Recht, derartige Ehen für ungültig zu erklären, noch keinen Gebrauch gemacht hätte (Boileau bei J. Launoy p. 319). 
Warum rief er, da er doch die Ehe vollständig gelöst wissen wollte, nicht von Anfang an auch das kirchliche Gericht an, wenn er wirklich überzeugt war, daß das Parlament nur über die bürgerliche Gültigkeit der Ehe zu entscheiden habe, in keiner Weise aber, auch nicht indirekt, über das Eheband und Ehesakrament?

Aus dem Gesagten ergibt sich, wie ich glaube, mit voller Sicherheit, daß die Behauptung, das Nichtigkeitsurteil der Parlamente betreffe bloß den bürgerlichen Vertrag und berühre in keiner Weise das Sakrament der Ehe, im Munde Ludwigs XIII. und seiner Minister und Räte tatsächlich durchraus nicht den Sinn hatte, in welchem die Gegenpartei sie nach dem Willen der Sprecher nehmen sollte, daB sie nichts anderes als eine kaum zu rechtfertigende restrictio mentalis war. In Wirklichkeit war nach ihrer Auffassung durch die Entscheidung ,non valablement contractéc dem Sakrament die notwendige Materie entzogen und dasselbe somit indirekt ebenfalls als nicht bestehend erklärt. $\left.{ }^{1}\right)$

Es steht also fest, daß das Pariser Parlament die Ehe des Herzogs von Orléans mit der Prinzessin Margareta von Lothringen dem Bande nach für ungültig erklärte, und daB das Urteil auch vom König und der Regierung in diesem Sinn aufgefaßt wurde. Die Entscheidung war gegründet auf den rapt de séduction. Ein Beweis, daß der Herzog wirklich verführt oder sein Wille in unzulässiger Weise beeinfluBt worden war, wurde offenbar gar nicht versucht, hätte aber auch, wenn er versucht worden wäre, unbedingt mißlingen müssen; denn Gaston gab später selbst aus freien Stücken die Erklärung ab, von einer Verführung könne gar keine Rede sein, vielmehr habe or selbst als erster den Wunsch geäußert, mit Margareta die Ehe zu schließen, und ebenso muBte es bei der Entschiedenheit, mit welcher er von Anfang an trotz allen Drängens von seiten des Königs an der Verbindung mit Margareta festhielt, als ausgeschlos-

1) Diese Wirkung einer solchen Entscheidung war aber in der von Jesus Christus selbst gesetzten Ordnung begruindet, nicht etwa in einem menschlich-staatlichen Gesetz. Ja der stautliche Gesetzgeber war gar nicht in der Lage, dieselbe zu verhindern. 
sen gelten, daß er dieselbe nicht mit freiem Willen, sondern nur gezwungen geschlossen hätte.

Demnach lag nichts anderes vor als Eheschließung ohne Genehmigung des Königs, in dessen Gewalt der Herzog stand. Auf Grund dieses Mangels allein erhob der König vor dem Parlament die Klage wegen rapt de séduction mit dem Antrag, die Ehe für nichtig zu erklären. Diese Tatsache ist sehr bemerkenswert, weil wir da an einem konkreten Beispiel sehen, wie Ludwig XIII., der Gesetzgeber von 1629 und 1639 , den rapt de séduction auffaßte, und wie weit er ihn ausdehnte. Wenn man die vom König selbst gegenüber der Ehe des Herzogs von Orléans betätigte Auffassung in seine Verordnungen hineintrug, dann war es unschwer möglich, auf Grund derselben jede ohne Genehmigung der Gewalthaber geschlossene Ehe wegen rapt de séduction für ungültig zu erklären.

Basdevant meint zwar, bei der Behandlung dieser Eheangelegenheit hätten sich die beteiligten Personen mehr von politischen als von rechtlichen Erwägungen leiten lassen, und man könne infolgedessen daraus kaum sichere Rückschlüsse auf ihre Rechtsanschauungen ziehen. ${ }^{1}$ ) Allein dieser Einwand trifft m. E. nur zu hinsichtlich der Art, wie der Fall auf der Versammlung des Klerus erledigt wurde; denn von dieser Versammlung kann man mit großer Wahrscheinlichkeit behaupten, daß sie zu einem anderen Ergebnis gekommen wäre, wenn nicht politische Rücksichten sehr stark mitgespielt hätten. ${ }^{2}$ ) Ganz anders dagegen liegen die Dinge bezüglich des vor dem Parlament geführten Prozesses. Hier traten nämlich gar keine Gedanken und Auffassungen zutage, die nicht vollständig in die damalige Gesetzgebung und insbesondere in die Theorie der Juristen und in die Praxis der Parlamente hineingepaßt hätten; vielmehr führten schon vorher und namentlich auch unmittelbar nachher zahlreiche Prozesse, die von Politik gewiß nicht beeinflußt.

1) Jules Basdevant, Des rapports de l'Église et de l'État dans la législation du mariage du concile de Trente au Code civil, Paris 1900, p. 110.

2) Siehe die Bemerkungen von Dupleix und Pothier im Code matrimonial II p. 813. 
waren, unter den nämlichen Voraussetzungen zum nämlichen Resultat.

\section{$\S 5$.}

Die Deklaration von 1639 .

Die Verordnung von 1629 hat, wie schon bemerkt, infolge des Widerstandes der Parlamente keine praktische Geltung erlangt. Man war darum für die rechtliche Beurteilung der in Frankreich so sehr verpönten Ehen ohne elterliche Genehmigung nach wie vor auf die alten Verordnungen von 1556 und 1579 angewiesen. Von diesen enthielt die erstere unzweifelhaft nur ein Verbot solcher Eben; aber auch die letztere konnte, vor allem wohl wegen ihrer Unklarheit und Unbestimmtheit, den Bedürfnissen der Praxis nicht genügen, und so ist es begreiflich, daß der Ruf nach einer neuen, besseren Verordnung immer wieder erscholl. Namentlich haben, wie berichtet wird, die beiden Generaladrokaten Bignon und Talon bei jeder sich bietenden Gelegenheit auf die dringende Notwendigkeit einer durchgreifenden gesetzlichen Regelung dieser Materie hingewiesen. Bereits im Jahre 1639 sollten ihre Wünsche erfüllt werden. Die unmittelbare Veranlassung zum Eingreifen des Gesetzgebers gab wiederum ein in hohen Gesellschaftskreisen spielender konkreter Fall.

Ein junger Edelmann namens Cinq-Mars, GroBstallmeister von Frankreich, wollte sich nämlich entgegen dem Willen seiner Mutter mit einem Fräulein Marie de l'Orme vermählen. Die Mutter wandte sich klagend an das Parlament von Paris ${ }^{1}$ ), und dieses erlie $B$ ein vorläufiges Verbot gegen die geplante Ehe. Im weiteren Verlauf der Angelegenheit wurde Generaladvokat Bignon vom König mit der Ausarbeitung einer neuen Verordnung über die EheschlieBung beauftragt. Die Verordnung wurde am 26. November 1639 in Saint-Germain-en-Laye publiziert als ,Declaration

1) Die Klage wegen rapt de séduction konnte schon vor AbschluB der Ehe erhoben werden, sofern nur Beweise dafür vorhanden waren, daß jemand einen Minderjährigen zur Eheschließung gegen den Willen der Gewalthaber zu veranlassen suchte. Vgl. M. Fournel, Traité de la séduction, Paris 1781, p. $313 \mathrm{~s}$. 
portant réglement sur l'ordre qui doit être observé en la célébration des mariages, et contre ceux qui commettent le crime de rapt". 1 )

Inhaltlich ist die Deklaration in sehr vielen Punkten eine Wiederholung der beiden Artikel 39 und 169 der Verordnung von 1629. Wie diese, ja noch deutlicher, aber immerhin nicht mit so klaren und bestimmten Worten, daß jede andere Auffassung vollständig unmöglich wäre, stellt sie den Mangel der elterlichen Ehegenehmigung dem rapt gleich. Schon der Titel ist bezeichnend. Obwohl nämlich die Verordnung nach ihrer Entstehungsgeschichte sich vor allem gegen die Ehe ohne Zustimmung der Eltern wendet, redet die Aufschrift doch bloß von der Eheschließungsform überhaupt und dann noch von dem Verbrechen des rapt. Der Aufschrift entspricht aber auch der Inhalt.

In einer längeren geschichtlichen Einleitung spricht der König nur von der durch seine Vorgänger vorgeschriebenen Eheschließungsform und von der Eheschließung ohne Konsens der Eltern sowie von den zahlreichen, schweren Mißständen, welche die Übertretung jener früheren Verordnungen und insbesondere die häufige Umgehung der elterlichen Autorität im Gefolge hat. Sobald er aber auf die Gegenwart zu sprechen kommt, bezeichnet er das letztere Vergehen ganz allgemein als ,,subornation et enlèvement" der Kinder und bald darauf geradezu als ,rapt". Ferner heißt es in Artikel 2, daß die Strafen des rapt aufrechterhalten bleiben sollen trotz einer etwa nachträglich gegebenen Zustimmung der Gewalthaber, und im Zusammenhang damit werden gewohnheitsrechtliche Bestimmungen, daß Kinder über 20 Jahren der elterlichen Genehmigung nicht mehr bedürfen, ausdrücklich aufgehoben; von einer etwaigen nachträglichen Zustimmung der geraubten Person ist nicht die Rede, wohl deshalb, weil eben der ganze rapt des Artikels 2 überhaupt nicht auf dem Mangel des Konsenses der letzteren Person, sondern nur auf dem Mangel des Gewalthaberkonsenses beruht; dieser Mangel wird also auch hier wieder dem rapt gleichgesetzt. Endlich wird in

1) Den Text derselben siehe im Code matrimonial I p. $121 \mathrm{ss.}$ 
Der Rapt de séduction als Ehehindernis nach gallikan. Kirohenr. 81

Artikel 3 verordnet, daB entführte Personen, die nach Wiedererlangung ihrer Freiheit unter Berufung auf ihre Großjährigkeit in die Ehe mit dem Entführer willigen, vollständig erbunfähig sein sollen ,,,conformément a ce que nous ordonnons contre les personnes ravies par subornation". Diese Bemerkung kann sich nur auf den vorausgehenden Artikel 2 beziehen und auf die Strafen, welche dort festgesetzt werden gegen die „,veuves, fils ot filles moindres de vingt-cinq ans, qui auront contracté mariage contre la teneur desdites ordonnances". Ebendiese Personen aber, d. h. die Minderjährigen, welche ohne Genehmigung der Eltern heiraten, werden hier in Artikel 3 als ,personnes ravies par subornation" bezeichnet, so daß wir also auch hier wieder die Gleichstellung der EheschlieBung ohne Genehmigung der Eltern mit dem rapt finden.

Von den sieben Artikeln der Deklaration sind Artikel 2 und 3 für unser Thema von Wichtigkeit. Artikel 2 bezieht. sich nur auf die Eheschließung ohne elterliche Genehmigung. Die älteren Vorschriften bezüglich derselben, nämlich das Edikt von 1556 und die Artikel 41, 42, 43 und 44 der Verordnung von Blois werden ausdrücklich wiederum bestätigt und in verschiedener Hinsicht ergänzt und verschärft. Uber die Gültigkeit oder Ungültigkeit der Ehen, die im Widerspruch mit Artikel 2 ohne Konsens der Eltern geschlossen wurden, wird jedoch eine klare Entscheidung nicht direkt gegeben. Sicher ist das eine, daß der König nicht den Mangel des elterlichen Konsenses als solchen für ein Ehehindernis erklären wollte. Wohl aber stellt er, wie bereits gezeigt worden ist, diesen Mangel dem rapt gleich, unterläßt es jedoch freilich wieder, daraus die entsprechende Folgerung zu ziehen und ausdrücklich die Ungültigkeit der Ehe auszusprechen. Allein diese Unterlassung hat nicht viel zu bedeuten. Denn wenn es feststand, daB der rapt jedesmal, sooft er vorlag, ein trennendes Ehehindernis bildete, und daß rapt immer anzunehmen sei, wenn bei der Ehe Minderjähriger die Zustimmung der Eltern fehlte, dann konnte der Gesetzgeber es ruhig der Praxis überlassen, aus diesen beiden Vordersätzen die 
notwendige Konsequenz auf die Nichtigkeit der Ehe zu ziehen. ${ }^{1}$ )

Was nun den ersteren Satz betrifft, so haben wir zwar in der zweiten Hälfte des 16. Jahrhunderts noch einen weiteren raptus-Begriff gefunden; aber dieser hat sich unter dem EinfluB der Verordnung von Blois in Bälde verloren, und in der Zeit, der unsere Deklaration angehört, war es längst ausgemacht, daß jeder rapt ein trennendes Ehehindernis bilde. Was den zweiten Satz anbelangt, so findet $\mathrm{m}$. E. die Ansicht, daß beim Mangel der elterlichen Ehegenehmigung eine unwiderlegliche Vermutung für den rapt bestehe, in der Deklaration eine sehr gute Stütze, zumal wenn man noch einige andere Punkte mitberücksichtigt. Der Gesetzgeber kannte nämlich recht wohl die Anschauung der Juristen, welche zum weitaus größten Teil für die Ungültigkeit der Ehe auf Grund der erwähnten Rechtsvermutung eintraten. Er kannte auch die Praxis der Parlamente, welche schon auf Grund der Verordnung von Blois die ohne Konsens der Eltern geschlossenen Ehen wegen rapt für ungültig zu erklären pflegten; ja er hatte sich diese Rechtsprechung wenige Jahre vorher gegenüber der Ehe seines Bruders selbst unbedenklich zunutze gemacht und vor dem Parlament die Klage auf Nichtigkeit der Ehe wegen rapt erhoben, obwohl von einem wirklichen rapt gar keine Rede sein konnte. Auch jetzt tat er nicht das mindeste, um jene unwiderlegliche Vermutung zu vernichten, sondern verschärfte umgekehrt die Maßnahmen gegen jene Ehen, indem er nicht nur ihre Gleichstellung mit dem rapt wiederholte, sondern auch noch neue schwere Strafen festsetzte, was natürlich die erwähnten Anschauungen der Juristen und die Praxis der Parlamente nur festigen und fördern konnte. Endlich können wir auch recht wohl den Grund angeben, warum der Gesetzgeber seine Absicht nicht so offen und klar aussprach, wie er es bei der Wichtigkeit der Sache hätte tun müssen. Er mußte nämlich fürchten, daß er durch offenes Auftreten gegen das kirchliche Eherecht in schwere Kämpfe mit der Kirche verwickelt würde,

1) Vgl. übrigens oben S. $66^{2}$. 
Der Rapt de séduction als Ehehindernis n. gallikan. Kirchenr. 83

deren Ausgang immerhin nicht so ganz sicher für ihn war. Ganz naturgemäß hatte er den Wunsch, diesen Kämpfen, wenn möglich, aus dem Wege zu gehen. Fir konnte das um so leichter tun und sich in seinen Verordnungen um so unbedenklicher eine weitgehende Zurückhaltung auflegen, als er begründete Hoffnung hatte, daß er mit Hilfe der Rechtsprechung das gewünschte Ziel dennoch im wesentlichen erreichen würde, eine Hoffnung, welche ihn in der Tat nicht getäuscht hat. ${ }^{1}$ )

Aus dem oben Gesagten können wir mit Sicherheit den Schluß ziehen, daß Ludwig XIII. die ohne elterliche Genehmigung geschlossenen Ehen wirklich für ungültig erklären wollte, und zwar wegen rapt de séduction. Wenn also die späteren Juristen in ihrer weitaus überwiegenden Mehrheit die Ansicht vertraten, daß bei Mangel des Elternkonsenses eine durch direkten Gegenbeweis nicht zu widerlegende Rechtsvermutung für den rapt bestehe, so konnten sie sich dafür mit vollem Recht auf den Gesetzgeber von 1639 berufen.

Abgesehen von der Ungültigkeit der Ehe soll die Eheschließung ohne Zustimmung der Eltern auch noch eine Reihe schwerer Strafen nach sich ziehen. Die schuldigen minderjährigen Personen sollen nämlich durch ihr Vergehen allein, also ohne daß Klage und Richterspruch notwendig wäre, ebenso wie ihre etwaigen Kinder und alle ihre sonstigen Erben zu jeder Erbfolge gegenüber ihren Eltern, Großeltern und übrigen Verwandten der geraden wie der Seitenlinie für immer unfähig sein und ebenso aller Rechte und Vorteile, die ihnen aus Eheverträgen oder Testamenten, durch die Gewohnheiten oder die Gesetze des Königreiches zufallen könnten, ja sogar des Rechtes auf den Pflichtteil verlustig gehen. Verfügungen, welche im Widerspruch mit dieser Verordnung zugunsten der beiden Gatten oder von diesen zugunsten ihrer Kinder getroffen werden, sind ungültig, und (lie Vermögensbestandteile, über welche in solch gesetzwidriger Weise verfügt wurde, sollen unwiderruflich dem

1) Ein solches behutsameres Vorgehen entsprach überdies durchaus dem Wesen des Gallikanismus, der nicht ein direkter Feind von Kirche und Religion ist und sein will (siehe unten $\S 8$ ). 
Fiskus verfallen sein und Krankenhäusern oder anderen frommen Werken zugute kommen. Den raptor aber trifftt die Strafe des raptus, d. h. also die Todesstrafe gemäß Artikel 42 der Verordnung von 1579.

Artikel 3 der Deklaration handelt nicht vom raptus seductionis, sondern vom raptus violentiae. Dies ergibt sich daraus, daß nicht nur Minderjährige, sondern Personen jeden Alters und Standes als Gegenstand dieses raptus in Frage kommen können ${ }^{1}$ ), und daß auch von einer erst nach träglich gegebenen Zustimmung der entführten Person zur Ehe die Rede ist. Im Einklang mit dem Kirchenrecht verordnet der König, daß eine gültige Ehe zwischen dem Entführer und der Entführten nicht möglich sein solle. solange diese sich in der Gewalt des ersteren befindet. Sofort aber entfernt er sich wieder vom Boden des Kirchenrechtes in seiner Stellungnahme zu einer späteren Eheschließung zwischen den beiden genannten Personen. Während nämlich das Tridentinum verordnet hatte, daß einer solchen Ehe nichts in den Weg gelegt werden solle, wenn die Entführte, vom Entführer getrennt und an einen freien und sicheren Ort gebracht, derselben freiwillig zustimmt, will der französische Gesetzgeber von einer derartigen Verbindung durchaus nichts wissen. Deshalb verordnet er, daß die Entführte, wenn sie großjährig ist und nunmehr, nach Wiedererlangung ihrer Freiheit, in die Ehe mit dem Entführer willigt, jedwedes Erbrecht gegenüber ihren Eltern und Verwandten verlieren soll, genau so, wie das in Artikel 2 bezüglich der ,,personnes ravies par subornation“ verfügt worden ist; desgleichen sollen die Eltern der Entführten, wenn sie etwa eine solche Ehe durch Rat oder Tat irgendwie begünstigen, und ihre Erben auch ihrerseits gegenüber dem betreffenden Kind kein Erbrecht mehr haben. Den zuständigen Staatsanwälten aber wird ausdrücklich aufgetragen, die Entführer, auch wenn von privater Seite keine

1) Gegenstand des rapt de séduction konnten nur Minderjährige sein, niemals Großjährige, weil dieser rapt ja ausschließlich ein Verbrechen gegen die Gewalthaber ist; ist ein Minderjähriger gewaltfrei, so kann er auch nicht mehr Gegenstand des rapt de séduction sein; vgl. Fournel p. 305 und unten $\S 7$ am Ende. 
Klage gestellt wird, mit allon Mitteln zu verfolgen, und den Richtern wird befohlen, dieselben zum Tod und Verlust des Vermögens zu verurteilen, ,ohne daß diese Strafe gemildert werden könnte“. Mit ähnlicher Strenge soll gegen jene vorgegangen werden, welche den Entführern bei ihrer Tat oder nachher Hilfe und Beistand geleistet haben.

Über die Frage, ob eine Ehe, die dennoch zwischen dem Entführer und der Entfiuhrten geschlossen wurde, gültig war oder nicht, spricht sich der König nicht aus. Er konnte das auch kaum; denn schließlich muß doch jeder Gesetzgeber voraussetzen, daß seine Anordnungen auch ausgeführt werden, und unter dieser Voraussetzung war die Frage gegenstandslos, da ja der Entführer immer mit dem Tode bestraft werden sollte.

In Artikel 4 endlich verbietet der König, um seinen Abscheu gegenüber dem Verbrechen des rapt möglichst kräftig zum Ausdruck zu bringen, allen Großen seines Reiches, irgendwelche Schritte für eine Begnadigung solcher Personen zu tun, welche wegen dieses Verbrechens für erbfolgeunfähig erklärt worden waren. Zudem erklärt er jeden etwa dennoch erlangten Gnadenakt im vorhinein für unguiltig und verbietet den zuständigen Hofbeamten die Ausfertigung und allen Richtern die Beachtung eines solchen Gnadenbriefes.

Mit der Deklaration von 1639 war die französische Gesetzgebung über den rapt de séduction in der Hauptsache abgeschlossen; nur eine einzige Verordnung ist aus der späteren Zeit noch zu erwähnen, nämlich die Deklaration Ludwigs XV. vom 22. November $1730^{1}$ ), die indes nichts Neues bringt, sondern nur den $Z$ weck hatte, eingerissene Mißbräuche zu beseitigen und den genauen Vollzug der früheren Verordnungen wieder einzuschärfen. In verschiedeten Gegenden nämlich, vor allem in der Bretagne, hatte sich die Gewohnheit gebildet, daß man in jedem unerlaubten Geschlechtsverkehr mit einer minderjährigen Frauensperson einen rapt de séduction erblickte. ${ }^{2}$ ) Falls das Mädchen mit

1) Text im Code matrimonial I p. 159 ss.

2) Diese Gewohnheit reicht in ihren Anfängen sebr weit zurück (siehe Code matrimonial I p. 442, II p. $875 \mathrm{sq}$.). Vielleicht hat sie an- 
der Behauptung, daß es verführt worden sei, klagte, so genügte schon der Beweis des intimen Verkehrs, um den schuldigen Mann zum Tod zu verurteilen. Zu einer Vollstreckung des Urteils kam es allerdings selten. Vielmehr konnte der Verurteilte, wenn das Mädchen ihn zur Ehe begehrte, durch Einwilligung in die Ehe sein Leben retten und die Freiheit wieder erlangen. Hatte er seine Zustimmung erklärt - und dies geschah natürlich unter diesen Umständen fast immer - , so wurde er, die Eisen an den Füßen, von einem Parlamentskommissär zur Kirche geführt, und dort wurde ohne Aufgebot, ohne Zustimmung des Pfarrers und ohne Erlaubnis des Bischofs, einzig und allein auf die Autorität des weltlichen Richters hin, die Ehe geschlossen. Ein solches Verfahren widersprach aufs schärfste dem Wortlaut und dem Geist der Ordonnanzen. Diese wollten die Ehen ohne elterliche Genehmigung verhindern; hier wurde der Wille der Eltern gänzlich umgangen. Sie wollten Mißheiraten hintanhalten; das Verfahren der Parlamente aber führte regelmäßig zum AbschluB der Ehe, indem der Verführer, der in Wirklichkeit häufig der Verführte war, unter Androhung des Todes zur Einwilligung gezwungen wurde. Endlich maßten sich die Gerichte dabei auch ein Begnadigungsrecht an, das ihnen durchaus nicht zustand.

Alle diese Mißbräuche wollte die Deklaration von 1730 beseitigen. $\mathrm{Zu}$ diesem $\mathrm{Zwecke}$ verordnete der König, daß unter dem rapt de séduction nur die Verführung einer minderjährigen Person (Sohn, Tochter oder Witwe) zur Eheschließung ohne Wissen oder gegen den Willen ihrer Gewalthaber zu verstehen, daß aber dieser rapt gemäß dem Artikel 42 der Verordnung von Blois und der Deklaration von 1639 unweigerlich mit dem Tod des Schuldigen zu ahnden sei, ohne daß irgendein Richter das Recht haben sollte, diese Strafe zu mildern oder dem Angeklagten die Wahl zu lassen zwischen dem Tod und der Ehe mit der Verführten; das sollte selbst dann gelten, wenn die Ver-

geknüpft an Art. 42 der Verordnung von Blois, die ron Verführung „sous prétexte de mariage ou autre couleur" redet; Fournel p. 308 s. meint, die Worte ,ou autre couleur" seien nichts weiter als ein Redaktionsfehler. 
Der Rapt de séduction als Ehehindernis n. gallikan. Kirchenr. 87

führte und deren Gewalthaber ausdrücklich die Ehe mit dem Verführer verlangten.

Des weiteren wird $v \in \mathrm{rfügt,}$ daß außerehelicher Geschlechtsverkehr nie mit dem Tode bestraft werden dürfe, abgesehen von besonders schweren Fällen, daß aber auch im letzteren Fall kein Richter das Recht habe, dem Schuldigen die Wahl zu lassen zwischen Tod und Ehe.

Ein letzter Artikel endlich schärft die genaue Beobachtung der früheren Verordnungen über die gewaltsame Entführung und über die Form der Eheschließung ein.

Bemerkt sei noch, daß die Deklaration von 1730 der erste Gesetzestext ist, der den Terminus ,,rapt de séduction“ anwendet zur Bezeichnung der Eheschließung ohne elterliche Genehmigung, und daß sie diesen rapt auch direkt als Ehehindernis anspricht. Die Theorie vom rapt de séduction war eben damals schon längst vollkommen ausgebildet und den Franzosen sozusagen in Fleisch und Blut iibergegangen. Wenn ferner Ludwig XV. mit aller Entschiedenheit verlangt, da $\beta$ die von seinen Vorgängern auf den rapt de séduction gesetzten barbarischen Strafen, insbesondere die Todesstrafe, von den Gerichten immer wirklich verhängt und ohne Gnade vollstreckt werden sollen, so können wir daraus entnehmen, wie wenig jenes Argument begründet ist, welches bei der Interpretation der Verordnungen Heinrichs III. und Ludwigs XIII. manchmal angewendet wird, das Argument nämlich : Dieser Artikel, dieser oder jener Abschnitt kann sich nur auf den raptus violentiae, nicht aber auf die bloße Eheschließung ohne elterliche Genehmigung beziehen, weil es ganz undenkbar ist, daß der König das letztere verhältnismäßig harmlose Vergehen mit dem Tode hätte bestrafen wollen. ${ }^{1}$ ) Wer möchte behaupten, daß Heinrich III. und Ludwig XIII. das nicht hätten wollen und verordnen können, was Ludwig XV. ohne Scheu mit den klarsten Worten verordnet hat?

1) Vantroys p. $260 \mathrm{sg}, 288$. 
$\S 6$.

Die Rechtsprechung der Parlamente.

Von großer Bedeutung für die Entwicklung des Rechtes über den rapt de séduction war die Rechtsprechung der Parlamente, die der Gesetzgebung zum Teil sogar vorauseilte. Ursprünglich waren in den Fällen des Raubes das kirchliche Verfahren über das Eheband und das weltliche Strafverfahren ganz unabhängig nebeneinander hergegangen. Aber schon in den Jahren 1541 und 1544 hatte sich das Pariser Parlament, das als oberstes Gericht des ganzen Landes das größte Ansehen geno $\beta^{1}$ ), dahin ausgesprochen, daß zunächst das Verfahren vor dem weltlichen Gericht durchzuführen sei, und daß der kirchliche Richter von jedem Eingreifen bzw, von der Weiterführung des Verfahrens abzusehen habe, wenn die Anklage wegen Raubes auf Leben oder Tod ging. ${ }^{2}$ ) Die Gründe, welche zu dieser fortan festgehaltenen Entscheidung führten, sind nicht recht klar. Vielleicht meinte man, daß die Ungültigkeit einer etwa geschlossenen Ehe in solchen Fällen notorisch sei, oder man hat die tatsächliche Auflösung des Ehebandes durch die Hinrichtung des Verurteilten ins Auge gefaßt. Vielleicht war noch mehr die Überlegung maßgebend, daß der kirchliche Richter, falls er sich für die Gültigkeit der Ehe aussprach, damit eine deutliche, wenn auch nur indirekte Kritik an dem Urteil des weltlichen Gerichtes geübt hätte, was ein ,Mißbrauch“ gewesen wäre. Sicher wollte das Parlament mit dèr erwähnten Entscheidung nicht eine Jurisdiktion über das Eheband als solches für sich in Anspruch nehmen ${ }^{8}$ ), aber dieselbe bedeutete gleichwohl eine schwere Behinderung der kirchlichen Gerichtsbarkeit, weshalb der Klerus im Jahre 1560 dagegen beim König Vorstellungen erhob $^{4}$ ), freilich ohne Erfolg.

1) E. Maugis, Histoire du Parlement de Paris I, Paris 1913, p. 368 ss.

2) Paponius, lib. XXII, tit. VI, arr. 2; L. Bouchel, La Bibliothèque ou trésor du droit françois III, nouvelle édition par J. Bechefer, Paris 1671, p. 48.

8) Bouchel II p. $680 . \quad$ 4) Code matrimonial I p. 183. 
Auf der Ständeversammlung von Blois am 8. Februar 1577 beschwerte sich der Klerus neuerdings wegen der Einmischung der weltlichen Gerichte in die kirchliche Ehejurisdiktion bezüglich der Verwandtschaft und in den Fällen des Raubes. In letzterer Hinsicht forderte er, daß das Recht des kirchlichen Richters, auch während des Strafverfahrens gegen den Räuber über das Eheband zu erkennen, anerkannt werde. ${ }^{1}$ )

Daraufhin untersagte eine Verordnung Heinrichs III. vom Februar 1580 im Artikel 25 den königlichen Richtern, das kirchliche Gerichtsverfahren unter dem Vorwand des Raubes zu behindern "sans grande et apparente raison". Zugleich wurden aber die Bestimmungen des Artikels 40 der Verordnung von Blois über die Einsegnung der Ehen von Gewaltunterworfenen nochmal eingeschärft. Das Pariser Parlament hat bei der Einregistrierung dem Artikel die vielsagenden Worte beigefügt: $Y$ sera pourvu selon les ordonnances et arrêts. Ebenso-fügte das Parlament von Grénoble der ganzen Verordnung die Klausel bei: Sans préjudice des appellations comme d'abus. ${ }^{2}$ )

Neue Vorstellungen in der gleichen Sache erhob der Klerus im Jahre 1605. Aber die Verordnung Heinrichs IV. von $1606^{3}$ ) brachte keinen besseren Erfolg als die eben genannte von 1580. Die Praxis der Parlamente wurde nicht nur nicht gemildert, sondern erfuhr um die Jahrhundertwende sogar eine wesentliche Verschärfung in dem Sinne, daß die Parlamente nunmehr dazu übergingen, über das Eheband als solches zu entscheiden.

Den Ausgangspunkt scheint dabei Artikel $\mathbf{4 0}$ der Verordnung von Blois gebildet zu haben, nicht etwa Artikel 42 derselben, der die bloße Verführung einer Minderjährigen zur Eheschließung ohne elterliche Genehmigung für ein todeswiurdiges Verbrechen, für einen raptus capitalis erklärte und so nach der herrschenden Gerichtspraxis eine

1) Mémoires du Clergé XIII, Paris 1740, col. 1022; Code matrimonial I p. 185.

2) Code matrimonial I p. 109; vgl. A. Esmein, Le mariage en droit canonique I, Paris 1891, p. 41 ss.

3) Code matrimonial I p. 112. 
bequeme Handhabe zur Ausschaltung der kirchlichen Gerichtsbarkeit über diese Fälle geboten hätte; denn die französischen Parlamente mochten sich nie dazu verstehen, über solche „Verbrecher" die Todesstrafe zu verhängen. Artikel 40 dagegen ist in der Hauptsache geltendes Recht geworden Er verlangte für die Gültigkeit der Eheschließung die Ein haltung einer bestimmten Form. Wer sollte über die Be obachtung dieser Anordnung wachen, wenn nicht die Beamten des Königs, der sie erlassen hatte? Und wer ander: sollte berufen sein, über die Rechtsfolgen einer Mißachtung zu entscheiden als die staatlichen Gerichte, insbesondere die Parlamente? Die Neuheit des Prinzips, daß staatliche Gerichte nach einer staatlichen Norm über Gültigkeit oder Ungültigkeit einer christlichen Ehe entscheiden sollten, und die Unklarheit ebendieser Norm mögen es erklären, daß auch dieser Artikel nicht ohne Schwierigkeiten und Hemmnisse sich durchsetzte. Doch hat das Pariser Parlament wenigstens seit dem Jahr 1595 die formlos geschlossenen Ehen regelmäßig für ungültig erklärt. $\left.{ }^{1}\right)$

Damit war der erste entscheidende Schritt geschehen. und es überrascht uns nicht, daß man nunmehr auch hinsichtlich der „Raub"ehen einen Schritt weiter ging und unter völliger Ausschaltung der kirchlichen Gerichte die weltliche Jurisdiktion auch auf das Eheband als solches ausdehnte, wie das in der Tat seit dem Beginn des 17. Jahrhunderts geschah. So hat am 31. August 1602 das Pariser Parlament auf die Klage des Vaters eine Ehe wegen rapt für ungültig erklärt, die ein junger Mann, ein königlicher Sekretär, mit einem übelbeleumundeten Mädchen geschlossen hatte. ${ }^{2}$ ) Im gleichen Sinn urteilte das Parlament von Rouen im Jahre $1608^{3}$ ), wiederum das Pariser Parlament in den Jahren 16224) und 1626.5 ) Von da an werden die

1) G. Lou et - J. Brod ea u, Recueil d'aucuns notables arrests donnez en la Cour de Parlement de Paris, dixième édition, Paris 1636, p. 481.

2) Paponius, lib. XXII, tit. VI appendix, arr. 4; Code matrimonial III p. $873 \mathrm{~s}$.

3) Bouchel III p. 47.

4) Bardet II, liv. 6, ch. 6 .

5) Code matrimonial II p. 874. - Vgl. zum Ganzen noch die Aus. führungen der Staatsanwälte in anderen ähnlichen Prozessen jener Zeit 
Urteile rasch häufiger, und aus dem vierten Jahrzehnt des 17. Jahrhunderts findet sich deren bereits eine ganze Anzahl. Durch die Deklaration von i 639 wurde diese Rechtsprechung bestätigt und befestigt und hat sich von da an bis zur Revolution ununterbrochen behauptet.

Wenn also in der Folgezeit eine ohne elterliche Genehmigung geschlossene Ehe von den Eltern angefochten wurde, so erging von seiten des Parlaments fast immer ein Nichtigkeitsurteil. Die Grundlage dieses Urteils bildete freilich durchaus nicht immer ausschließlich der rapt de séduction, sondern oft lag ein anderes trennendes Ehehindernis vor, nämlich die Klandestinität im eigentlichen Sinn. Man hatte ja, um die Durchführung der Verordnungen über die Notwendigkeit des elterlichen Ehekonsenses zu sichern, den Pfarrern unter strenger Strafe verboten, Ehen von gewaltunterworfenen Personen zu assistieren, wenn die Genehmigung der Gewalthaber nicht vorlag. Die Pfarrer verweigerten darum in solchen Fällen meistens die Trauung, und so waren die Kontrahenten, wenn sie die Genehmigung der Eltern nicht erlangen konnten, aber auch von ihrem Vorhaben nicht abstehen wollten, gezwungen, sich an einen anderen Priester zu wenden, der entweder überhaupt willfähriger war oder, da er Personen und Verhältnisse nicht genügend kannte, leichter getäuscht werden konnte. Solche Ehen, vor einem nicht zuständigen und nicht bevollmächtigten Priester geschlossen, waren nun allerdings auch nach kirchlichem Recht ungültig; dennoch stand das ganze Verfahren mit dem Geiste des Kirchenrechts in schroffem Widerspruch, da man es ja den Kontrahenten mit voller Absicht unmöglich machte, die vorgeschriebene Form einzuhalten. ${ }^{1}$ )

(Ba rdet I, liv. 2, ch. 17; II, liv. 5, ch. 11; II, liv. 2, ch. 47; insbesondere II, liv. 1, ch. B).

1) Die Klandestinität hat aber in der Praxis nur eine ganz untergeordnete Rolle gespielt neben dem rapt de séduction. Es war für den Kläger viel bequemer, dieses letztere Hindernis geltend zu machen, da er es nicht zu beweisen brauchte. Der Beweis lag ja schon in der Klagestellung als solcher, da ein mit der Eheschließung einverstandener Gewalthaber überhaupt nicht geklagt hätte. 
Aber auch wenn Klandestinität sicher nicht vorlag, konnte die ohne elterliche Genehmigung geschlossene Ehe dennoch auf Grund des rapt de séduction für ungültig erklärt werden, und das geschah sehr häufig; es ließe sich eine große Anzahl von Urteilen anführen, welche sich auf diesen rapt stützten, obwohl in Wirklichkeit nur die elterliche Genehmigung fehlte und von irgendeiner Verführung gar keine Rede war. Nur zwei markante Beispiele seien herausgegriffen:

Ein gewisser Pollart, Bürger von La Rochelle, hatte mit dem Gerichtsbeamten Pichon im Mai 1685 eine Vereinbarung getroffen über die Verheiratung seiner Tochter Jeanne mit Pichons Sohn Joseph; später aber wollte er ohne ersichtlichen Grund von der Erfüllung dieser Vereinbarung nichts mehr wissen. Das Mädchen, das inzwischen in einem klösterlichen Institut untergebracht war, verließ dasselbe im Herbst 1687 und schloß mit Dispens von zwei Aufgeboten in Gegenwart von vier Zeugen vor einem bevollmächtigten Priester, aber ohne Wissen des Vaters mit dem jungen Pichon die Ehe. Pollart legte gegen diese Ehe appel comme d'abus ein. Abgesehen von einigen bedeutungslosen Unregelmäßigkeiten in der Verkündigung des einen Aufgebotes und der Dispensation von den beiden anderen lag nichts weiter vor als der Mangel der Zustimmung des Brautvaters. Dennoch wurde die Ehe durch Urteil des Pariser Parlamentes vom 10. Januar 1689 wegen rapt de séduction für ungültig erklärt. Staatsanwalt Bignon machte sich in seinem Plädoyer selbst den Einwand, daß doch nach dem Konzil von Trient die elterliche Genehmigung zur Gültigkeil der Ehe nicht notwendig sei. Er antwortete darauf, daß der rapt de séduction auch nach kirchlichem Recht ein trennendes Ehehindernis bilde, und daß derselbe immer vorliege, wenn der Konsens des Vaters fehlt. ${ }^{1}$ )

Der dreiundzwanzigjährige Musketieroffizier Herr von Bapaume lernte im Hause seiner Mutter in Paris ein Mädchen aus Lüttich, namens Maria Ida Cabo kennen. Als die Cabo wieder nach Lüttich zurückgekehrt war, ging er eben-

1) Code matrimonial II p. $\mathbf{8 6 7} \mathbf{s 8 .}$ 
falls dorthin und schloß mit ihr unter Einhaltung der vorgeschriebenen Form, aber ohne Wissen seiner Mutter die Ehe. Als die Frau von Bapaume davon Kenntnis erhielt, strengte sie eine Klage wegen rapt an. Die beklagte Cabo machte geltend, daß die Ehe in Lüttich geschlossen sei und nach den dortigen Gesetzen, nicht nach den französischen, die sieals Ausländerin nicht kannte, beurteilt werden müsse ${ }^{1}$ ); daß die erste Anregung zur Eheschließung nicht von ihr, sondern von dem Herrn von Bapaume ausgegangen sei, wie sie durch Briefe beweisen könne; endlich, daß ein dreiundzwanzigjähriger Offizier doch schwerlich Gegenstand und Opfer einer Verführung hinsichtlich der Ehe sein könne. Trotzdem wurde die Ehe in zwei Instanzen für ungültig erklärt und die Cabo zur Strafe auf die Dauer von drei Jahren aus dem Gerichtsbezirke von Paris verbannt. ${ }^{2}$ )

Es liegt nun allerdings auch eine Reihe von Urteilen vor, durch welche Ehen, die von Minderjährigen obne Genehmigung der Gewalthaber geschlossen worden waren, trotz dieses Mangels für gültig erklärt wurden, wenigstens dem Bande nach, manchmal sogar auch hinsichtlich der bürgerlichen Wirkungen. Allein von der Gesamtzahl aller derartigen Fälle muß man vor allem diejenigen wegnehmen, in denen es sich um Männer zwischen 25 und 30 Jahren handelte; denn die öfter vertretene Ansicht, daß auch diese zur Gültigkeit der Ehe der Genehmigung der Eltern bedürften, ha屯 nie allgemeine Anerkennung gefunden. Ebenso sind wegzunehmen manche Fälle, in denen die während der Minderjährigkeit geschlossene Ehe von dem inzwischen volljährig gewordenen Gatten noch längere Zeit ohne Anfechtung fortgesetzt oder etwa gar noch ausdrücklich an: erkannt worden war. ${ }^{3}$ )

1) Dieser Umstand wäre einige Jahrzehnte früher wohl berücksichtigt worden; vgl. ein Urteil des Pariser Parlaments vom 26. März 1624 (Mémoires du Clergé V col. 8839s.) und ein Urteil des Parlaments der Provence vom 11. Juni 1662 (ibid. col. 829 sa.). Inzwischen hatte aber namentlich die Deklaration vom 16. Juni 1685 (ibid. col. 755s.) die Eheschließung im Ausland bzw. die Einwilligung und Mitwirkung der Eltern hierzu unter strenge Strafe gestellt, freilich ohne sie für ungültig zu erklären.

2) Code matrimonial II p. $874 \mathrm{~s}$.

3) Siehe die Urteile des Pariser Parlaments rom 26. März 1654, 
Bei den Urteilen, die dann noch übrigbleiben, handelt es sich fast durchweg um besonders gelagerte Fälle. Das eine Mal konnte die bestrittene Minderjährigkeit nicht sicher bewiesen werden, ein anderes Mal sprach vieles dafür, daß die Eltern die jetzt von ihnen angefochtene Ehe vor ihrem Abschluß wenigstens stillschweigend gebilligt hatten; ein drittes Mal hatten die Eltern, obwohl sie von der Eheschließung wußten, lange nichts gegen dieselbe unternommen, woraus man auf nachträgliche Billigung derselben schließen konnte. ${ }^{1}$ ) In manchen anderen Fällen handelte es sich um eine offenbar ganz unvernünftige Weigerung ${ }^{2}$ ) oder um pflichtvergessene Eltern, die sich früher lange Zeit wenig oder gar nicht um das betreffende Kind gekümmert hatten, weshalb sie auch jetzt kein Recht und keine Gewalt mehr über dasselbe sollten beanspruchen können. ${ }^{3}$ ) In einigen wenigen Fällen endlich scheint die Tatsache, daß der klagende Vater dem reformierten Bekenntnisse angehörte, für die Abweisung der Klage bestimmend gewesen zu sein.4)

In all diesen Fällen wurde demnach ein Beweis, daß ler Minderjährige nicht verführt war, weder verlangt nocli erbracht, sondern die Klage wurde lediglich deshalb abgewiesen, weil die Klagesteller, Eltern oder Vormünder, aus irgendwelchen anderen Gründen als ,, non recevables". erschienen. Die Rechtsvermutung der Verführung wurde also hier nur durch eine Art Gegenvermutung, die auf rein äußeren Gründen beruhte, beseitigt, nicht durch einen tatsächlichen Gegenbeweis. Solche tatsächliche Gegenbeweise wurden vielmehr auch dort, wo sie zweifellos erbracht waren, regelmäßig nicht beachtet. Auch wenn die Beweisaufnahme

vom 4. August 1664 und vom 1. März 1691 (Code matrimonial II p. 569, 570s., 572).

1) Vgl. besonders das Urteil des Pariser Parlaments vom 27. Juli 1657 und das Urteil des Parlaments von Dijon vom 26. Januar 1683 (Code matrimonial II p. 569, 574).

2) Urteil des Pariser Parlaments vom 27. Januar 1663 (ibid. p. 569s.).

3) Siehe das Urteil vom 1. März 1691 (ibid. p. 572) und das vom 7. Juli 1727 (ibid. p. 5748.).

4) Urteil des Pariser Parlaments vom 15. Mai 1648 (ibid. p. 562). Vgl. auch das Urrteil desselben Parlaments vom 30. Juli 1664 (Mémoires du Clergé V col. 833 ss., insbesondere col. 844s.). 
klar ergab, daß die "Verführte“" alles getan hatte, um ihr Ziel, die Ehe mit dem „Verführer" zu erreichen ${ }^{1}$ ), auch wenn sie ihre Ehe selbst noch im Prozeß mit allem Nachdruck verteidigte und zu retten suchte ${ }^{2}$ ), ja selbst wenn die „Verführerin" beweisen konnte, da $\beta$ die erste Anregung gar nicht von ihr ausgegangen war, und daB sie nur ungern von dem „Verführten" sich zur Einwilligung in die Ehe hatte bewegen lassen ${ }^{3}$ ): die Ehe wurde dennoch wegen rapt de séduction für ungültig erklärt. Den entgegenstehenden Tatsachen trug das Gericht allenfalls dadurch Rechnung, daß es den „Verführten“ in eine Buße zugunsten der ,Verfiihrerin" verurteilte.")

Normal gelagerte Fälle aber, in denen trotz des Mangels der elterlichen Zustimmung eine Ehe für gültig erklärt wurde, sind derart selten, daß man ruhig den Satz anwenden kann: Ausnahmen bestätigen nur die Regel.

Versuche, ein von einem Parlament gefälltes Nichtigkeitsurteil durch Anrufung einer römischen Instanz umzustoßen, sind wohl nie gemacht worden, wären übrigens bei der Eifersucht, mit welcher die Parlamente ihre Jurisdiktion über die Ehe hüteten, sicher erfolglos geblieben und hätten nur schwere Strafen für die Appellierenden nach sich gezogen. Nur ein einziger Fall ist mir bekannt, der hier erwähnt zu werden verdient. Das Parlament von Aix hatte im Jahre 1705 eine zwischen Joseph Coulon und Gabriele Arnaud geschlossene Ehe für ungültig erklärt, weil die noch minderjährige Gabriele die Genehmigung ihres Vaters nicht gehabt hatte. Als Coulon später, wie es scheint in Italien, eine anderweitige Ehe schließen wollte, wurden die römischen Behörden auf jene erste Ehe aufmerksam. Die Sache kam zur Verhandlung vor der Konzilskongregation, und diese erklärte durch Entscheidung vom 17. November 1708 das Urteil des Parlaments von Aix für nichtig und die Ehe

1) Bardet II, liv. 2, ch. 47; II, liv. 6, ch. 29.

2) Code matrimonial II p. 879s

3) Fall Bapaume-Cabo; siehe oben S. $92 \mathrm{f}$.

4) Code matrimonial II p. 874 (Urteile des Pariser Parlaments vom 23. Juni 1626 und vom 18. März 1651). 
zwischen Coulon und Gabriele Arnaud für gültig und zu Recht bestehend.1)

Was die Bestrafung des rapt de séduction betriffit; so mochten sich die Parlamente fast nie dazu verstehen, die in den königlichen Verordnungen immer wieder festgesetzte Todesstrafe über den raptor zu verbängen. ${ }^{2}$ ) Die gewöhnlichen Strafen waren und blieben vielmehr die Enterbung, die aber zunächst die „Verführte" traf, sodann für den Verführer Geldstrafen, Gefängnis oder Verbannung. Im allgemeinen kann man nicht sagen, daß die verhängten Strafen außergewöhnlich streng gewesen wären, wenn man die Auffassung der Parlamente, daß Verleitung einer minderjährigen Person zur Eheschließung ohne Genehmigung der Gewalthaber ein schweres Verbrechen sei, berücksichtigt. ${ }^{8}$ )

\section{$\S 7$.}

Der rapt de séduction in der Doktrin.

Die bisherige Darstellung hat gezeigt, daß zwischen der kirchlichen Gesetzgebung und der Gesetzgebung des französischen Staates hinsichtlich der Notwendigkeit des elterlichen Ehekonsenses ein Widerspruch bestand. Während nämlich die Kirche diesen Konsens zwar als sehr wünschenswert, aber immerhin als unwesentlich und entbehrlich er-

1) Analecta Juris Pontificii XXVII, 1888, p. 375s.; Riganti, Commentaria in regulas . . . Cancellariae Apostolicse, in reg. 49, n. 131.

2) Blondeau II p. 77 sagt hierüber: En France où les Juges se persuadent que toutes les peines sont arbitraires, quoy que les Ordonnances les prononcent, ils se relâchent volontiers de la rigueur de la loy. M. Fournel p. 326 rechnet es seiner Zeit geradezu zur Ehre an, daB die beleidigten Familien (entgegen dem Gesetz!) regelmäßig lieber nachträglich in die Ehe willigen, als den Beleidiger der Todesstrafe überlief ern wollten.

3) Dagegen hatte bei dem Vergehen, das man sonst als raptus seductionis zu bezeichnen pflegt, $d$. h. bei wirklicher Entführung einer zustimmenden Minderjährigen aus dem väterlichen Haus zum Zweck der Ehescbließung, der Täter die Todesstrafe zu gewärtigen. Siehe das Urteil des Parlaments von Dijon vom 10. Februar 1738 gegen den Marquis de Tavannes (Code matrimonial II p. 620) und Fournel p. 331. Vgl. auch das Todesurteil gegen Pierre de Chaulnes (Code matrimonial II p. 879). 
klärte, verlangte ihn der Staat mit größtem Nachdruck. Die französischen Könige waren aber bei all ihren Maßnahmen in dieser Sache sichtlich von dem Bestreben geleitet, einen offenen Konflikt mit der Kirche zu vermeiden, und gingen darum nie so weit, dem Drängen der Juristen zu folgen und den Mangel des elterlichen Konsenses direkt als trennendes Ehehindernis zu erklären. Man erreichte das gewünschte Ziel in anderer Weise, nämlich dadurch, daß man den Begriff des raptus, welch letzterer auch von der Kirche als trennendes Ehehindernis anerkannt war, dergestalt erweiterte, daß auch die Eheschließung ohne Konsens der Eltern oder sonstigen Gewalthaber darunter fiel.

Den entscheidenden Anfang damit machte Heinrich III. in der Verordnung von Blois, indem er wenigstens indirekt erklärte, daß ein ehehindernder raptus auch durch bloße Verführung Minderjähriger zur Eheschließung ohne Wissen und Willen der Eltern begangen werden könne. Zugleich bestimmte er, daß bei der Untersuchung über die Verführung und bei der Bestrafung des durch die Verführung begangenen raptus die Zustimmung der verführten Person außer Betracht zu lassen sei, und deutete an, daß man ein besonderes Merkmal für das Vorliegen von Verführung in dem Mangel des elterlichen Konsenses erblicken könne. ${ }^{1}$ ) Nimmt man dazu die Tatsache, daß man in Frankreich schon vor dieser Verordnung die bloße Eheschließung ohne elterliche Genehmigung als raptus bezeichnete, also einen raptus ohne abductio mulieris kannte ${ }^{2}$ ), und daß nach dem römischen Recht, an welches sich der König anschloß, die Zustimmung zum raptus immer auf die Verführung des Weibes durch den Mann zurückgeht, dann wird man sich nicht darüber

1) Siehe oben S. 64 ff.

2) Siehe oben S. 62 ff. Auch der bloße Zwang zur Eheschließung unter Mißbrauch obrigkeitlicher Gewalt und Mißachtung des Willens der Gewalthaber wurde manchmal als rapt bezeichnet; vgl. Art. 3 der Verordnung Karls IX. vom Jahre 1560 (Code matrimonial I p. 105) und Art. 281 der Verordnung von Blois (ibid. p. 108). Dadurch, daß die französische Doktrin schon vorher die Ansicht vertrat, daß die abductio zum Begriff des raptus nicht erforderlich sei, wurde die Ausbildung der Theorie vom rapt de séduction wesentlich erleichtert.

Zeitschrift für Rechtsgeschichte. XLIII. Kan. 1 bt. XII. 
wundern, daß die Parlamente auf Grund dieser Verordnung dazu übergingen, die ohne elterliche Einwilligung geschlossenen Ehen minderjähriger Personen wegen raptus, begangen durch Verführung, für ungültig zu erklären.

Der Weg, auf welchem man zur Ungültigkeitserklärung gelangt war, war freilich etwas umständlich, aber es war immerhin ein Weg, und die französischen Juristen betraten ihn mit aller Entschiedenheit, da sich ihnen ein besserer nicht darbot. ${ }^{1}$ ) So scheinen die beiden Sätze, daß durch Verführung ebensogut wie durch Anwendung physischer Gewalt raptus begangen werden könne, und daß Verführung beim Mangel der elterlichen Genehmigung immer zu vermuten sei, sehr rasch in den weitesten Kreisen zur Anerkennung gelangt zu sein.

Schon etwa seit dem Ende des 16. Jahrhunderts war der rapt de séduction das Mittel, welches die Parlamente anwendeten, um die ohne elterlichen Konsens geschlossenen Ehen minderjähriger Kinder für ungültig zu erklären ${ }^{2}$ ), die Theorie von demselben war also offenbar bereits damals im wesentlichen entwickelt. In der Tat finden sich ihre Hauptelemente schon bei den ersten Kommentatoren der Verordnung von Blois, Brisson und Théveneau ${ }^{3}$ ), und in den Plädoyers der Staatsanwälte am Pariser Parlament Servien, Talon und Bignon sehen wir sie bereits im ersten Drittel des 17. Jahrhunderts klar und deutlich dargestellt.4) Thre volle Ausgestaltung erfuhr sie dann in der Folgezeit im Anschluß an die Deklaration von 1639 und an die Rechtsprechung. Pothier formuliert sie klar in folgender Weise:

Verführung liegt dann vor, wenn eine minderjährige Person ohne Anwendung physischer Gewalt durch verwerfliche Mittel veranlaßt wird, ohne Wissen und Willen der

1) Auch später wurde von französischen Juristen noch öfters der Wunsoh geäußert, die Könige möchten den Mangel des Gewalthaberronsenses als solchen zu einem trennenden Ehehindernis erklären.

2) Conférences ecclésiastiques de Paris sur le mariage II, 3. édition, Paris 1748, p. $4198 \mathrm{~s}$.

3) Oben S. 61 ${ }^{2}, 65^{1}, 66^{1}$.

4) Oben S. $90^{\circ}$. 
Eltern eine Ehe zu schließen. Diese Verführung ist nach französischem Recht ebenso ein Ehehindernis wie der rapt, ja sie gilt geradezu als die eine Art des rapt, nämlich als rapt de séduction neber der zweiten Art, dem rapt de violence. Die Verführung wird von Rechts wegen immer präsumiert, wenn ein gewaltunterworfenes Kind sich ohne Zustimmung der Gewalthaber verheiratet.1)

Fast noch mehr tritt die Verführung in den Hintergrund bei Fo urnel. Zwar definiert er den rapt de séduction als ,l'usage de quelques manœuvres pour engager un fils ou une fille de famille à contracter mariage à l'insçu et contre le consentement de ses parens " ${ }^{2}$ ), erklärt aber andererseits, daß derselbe unmittelbar die Familie treffen, und Autorität verletzt wird, so sehr, daB ein Minderjähriger, der keine Familie und keinen Vormund hat, überhaupt nicht Gegenstand des rapt de séduction sein kann, sowenig wie eine großjährige Person. Offen gibt er zu, daß man dieser rapt auch in Frankreich nicht kennen wïrde, wenn es nicht dort Gesetze gäbe, welche die Ehen der Hauskinder von der Zustimmung der Eltern abhëngig machen, da gerade die Verletzung der elterlichen Autorität den rapt de séduction charakterisiere. ${ }^{2}$ )

Die französischen Juristen haben sich nicht sonderlich bemüht, ihre Theorte von der Verführung zu beweisen. Im allgemeinen begnügten sie sich damit, die einzelnen Behauptungen aufzustellen und sie als etwas Selbstverständliches zu behandeln, an dem vernünftigerweise niemand zweifeln könne. Mit den entgegenstehenden Entscheidungen des Konzils von Trient fand man sich ab, zumeist, indem man erklärte, daB die Disziplinardekrete des Konzils in Frankreich nicht rezipiert seien und infolgedessen dort überhaupt keine Geltung hätten. Bezüglich des Anathems aber, welches das Konzil über jene ausgesprochen hatte, die fälschlich behaupten, daß die ohne elterliche Genebmigung geschlossenen Ehen der Kinder ungültig seien und die Eltern sie gültig oder ungültig machen könnten, pflegte man zu

1) R. J. Pothier, Traité du contrat du mariage n. 228, 229, 326.

2) p. 311. 2) p. 3058 . 
sagen, daß es sich nur auf die Häretiker beziehe, welche lehrten, daß solche Ehen kraft natürlichen oder positiv göttlichen Rechtes ungültig seien, und daß darum jene Befugnis der Eltern auf dem gleichen Rechte beruhe und durch menschliche Gesetze gar nicht aufgehoben werden könne.

Wohl der schwächste Punkt in der ganzen Theorie vom rapt de séduction war die Aufstellung der Rechtsvermutung, daß bei Eheschließung eines Minderjährigen ohne elterliche Genehmigung immer Verführung vorliege, zumal man dieselbe geradezu als an sich unwiderleglich betrachtete. ${ }^{1}$ ) Die Juristen konnten sich allerdings dabei mit gutem Grund auf den Gesetzgeber berufen, und es ist nicht an dem, als ob sie die erwähnte Rechtsvermutung in ganz willkürlicher Weise in die königlichen Verordnungen hineingetragen hätten. Trotzdem wird man sie mehr ihnen als dem Gesetzgeber zurechnen müssen; denn dieser hat im großen und ganzen nur das sanktioniert, was die Juristen längst gefordert und in der Rechtsprechung zum Teil schon früher praktisch betätigt hatten, und außerdem waren die Verordnungen nicht so klar und bestimmt gefaßt, daß eine mildere Auslegung nicht möglich gewesen wäre, zumal bei der oft sehr weitgehenden Freiheit, die sich die französischen Parlamente im allgemeinen gegenüber den königlichen Verordnungen wahrten, auch gegenüber jenen, die den rapt de séduction betrafen.

Eine möglichst milde Auslegung der einschlägigen $\mathrm{Ge}-$ setzestexte wäre hier um so mehr am Platz gewesen, als die fragliche Rechtsvermutung in den tatsächlichen Verhältnissen absolut nicht begründet ist. Man sagte, ein Kind würde sich nie zu einer derartigen Mißachtung der elterlichen Autorität verstehen, wenn es nicht von anderer Seite verführt wäre. Allein die traurige Erfahrung zeigt nur zu oft, da $B$ sich minderjährige Kinder gegenüber ihren Eltern viel schlimmere Dinge zuschulden kommen lassen, als es die eigenmächtige Wahl eines Lebensgefährten oder einer Lebensgefährtin ist. Schließlich sind ja doch die Kinder und nicht die Eltern am meisten und unmittelbarsten an

1) Oben S. $94 \mathrm{f}$. 
Der Rapt de séduction als Fhehindernis n. gallikan. Kirchenr. 101

dieser Wahl interessiert, so daß es begreiflich ist, wenn sie dieselbe nach eigenem Wunsch und Willen treffen wollen.

Aber auch die andere Behauptung, daB die Verfühiung ebenso wie die Anwendung physischer Gewalt nach bürgerlichem wie nach kirchlichem Recht das trennende Ehehindernis des raptus begründe, ist, wenngleich nicht durchweg unrichtig ${ }^{1}$ ), so doch in der maßlosen Ausdehnung, in welcher man sie in Frankreich aufgestellt hat, vollkommen unhaltbar; denn ein auf dem Mangel der Konsensfreiheit basierendes Ehehindernis kann man vernünftigerweise nur dort annehmen, wo die notwendige Freiheit entweder sicher fehlt oder ihr Mangel wenigstens mit guten Gründen zu vermuten ist. Bei der Eheschließung Minderjähriger ohne elterliche Genehmigung ist aber regelmäßig weder das eine noch das andere der Fall, selbst dann nicht, wenn wirklich von dritter Seite durch Greschenke, Versprechungen oder Zureden auf die Minderjährigen eingewirkt wird; denn zum Abschluß einer gültigen Ehe genügt vollständig und muß genügen jener Grad vom Freiheit, welcher unter Menschen normalerweise unschwer erreicht werden kann und bei anderen ähnlich wichtigen Akten vom natürlichen wie vom positiven Gesetz als genügend erklärt wird. Diese wesentliche Freiheit des Konsenses wird aber nicht schon durch Schmeicheleien, Geschenke, Versprechungen oder Bitten, auch nicht durch Zureden oder einfaches Drängen aufgehoben; sonst müßte man zweifellos einen recht beträchtlichen Teil nicht nur der Ehen von Minderjährigen, sondern auch viele Ehen von Großjährigen ${ }^{2}$ ) für ungültig ansehen, und zwar sicher noch öfter wegen des Druckes, den die Eltern auf ihre Kinder, vor allem die Mädchen, bei der Eheschließung ausüben, als wegen einer Verführung von seiten des anderen

1) Auch das kirchliche Recht jener Zeit hat einen raptus, begangen an einem zustimmenden Weib, gekannt; aber es verlangte zu demselben vor allem immer eine wirkliche abductio (de loco in locum) und nahm ihn außerdem nur dann an, wenn die Entführte nicht vor der Entfuihrung ihre Zustimmung zur Ehe gegeben hatte.

8) Wenn nämlich die „Verführung“ wirklich die Freiheit aufhöbe, könnte man ihre Wirkung nicht durch Gesetz auf die Minderjährigen einschränken, sondern müßte von Fall zu Fall untersuchen. 
Brautteils oder sonstiger dritter Personen. Damit käme man zu Folgerungen, die den sicheren Bestand der Ehen und darum das Wohl der Familien und der ganzen menschlichen Gesellschaft schwer gefährden, ein Beweis, daB der eine Vordersatz falsch ist, der Satz nämlich, daß durch Versprechungen, Geschenke und dergleichen die Freiheit der Eheschließung ebenso aufgehoben werde wie durch physische Gewalt. Aber freilich, den französischen Juristen jener Zeit war es ja auch gar nicht darum zu tun, die Freiheit. der Minderjährigen bei der Wahl des Gatten zu schützen; sie wollten vielmehr nur den entscheidenden Einfluß der Eltern auf jene Wahl sicherstellen, und einzig und allein um dieses Zweckes willen stellten sie die genannten unhaltbaren Sätze auf, da sie den Gesetzgeber nicht dazu veranlassen konnten, den Mangel des elterlichen Ehekonsenses als solchen zu einem trennenden Ehehindernis zu erklären. $\left.{ }^{1}\right)$

Nicht ganz soweit wie die Juristen gingen die gallikanischen Theologen. Zwar verteidigten auch sie den Satz, daß bei Minderjährigen die Verführung ebenso wie die physische Gewalt das kirchenrechtliche Ehehindernis des raptus begründe, und sie suchten diesen Satz auch zu beweisen. Gerbais z. B. sagt, daB das Charakteristische des vom Tridentinum neu aufgestellten Ehehindernisses des raptus eben die Verführung sei, nicht die Gewalt, da die letztere schon an und für sich nach wie vor ein Ehehindernis bilde, und da das Hindernis des raptus auch noch fortdauere, wenn die Gewaltanwendung aufgehört hat, solange bis die Entführte vom Entführer vollständig getrennt und an einen freien und sicheren Ort gebracht wird. Auch liege das Erbärmliche und Ungerechte des raptus nicht immer in der Anwendung offener Gewalt, sondern sehr oft auch in der

1) Manche Juristen vertraten übrigens die Ansicht, daß nach den Verordnungen von 1579 und 1639 der Mangel des Gewalthaberkonsenses als solcher in Frankreich ein trennendes Ehehindernis bilde (vgl. Code matrimonial II p. 54788.); sie vermochten aber damit in der Praxis nicht durchzudringen. Immerhin finden sich manche Urteile, durch welche Ehen von Minderjährigen, denen der Konsens der Gewalthaber fehlte, eben wegen dieses Mangels, aber ohne formelle Bezugnahme auf den rapt de séduction für "abusif" und darum nichtig erklärt wurden (Code matrimonial II p. 539, 5428.). 
Der Rapt de séduction als Ehehindernis n. gallikan. Kirchenr. 103

Verführung, die Herz und Sinn einer jugendlichen Person gefangennehme und ihr die Freiheit der Entscheidung raube. $\left.{ }^{1}\right)$

Den anderen Satz aber, daß beim Fehlen der elterlichen Zustimmung immer eine geradezu unwiderlegliche Rechtsvermutung für das Vorliegen der Verführung bestehe, ließen sie nicht im vollen Umfang gelten, da sie wohl einsahen, daß er mit den Dekreten des Konzils von Trient nicht vereinbar sei. Praktisch freilich war der Unterschied nicht von Bedeutung; denn mit Rücksicht auf die ständige, gleichmäßige Rechtsprechung der Parlamente gaben auch die Theologen wiederum zu, daB beim Mangel des elterlichen Konsenses ,fast immer" "2) Verführung vorliege. Nur das wollten und konnten sie grundsätzlich nicht zugeben, daB jener Mangel in allen Fällen und notwendig den RückschluB auf die Verfïhrung verlange, weil diese Auffassung in direktem Widerspruch mit dem Konzil von Trient stand.

Einen interessanten Beleg dafür, daß zwischen der Lehre der Juristen und jener der Theologen kein wesentlicher Unterschied bestand, finden wir in den „Conférences ecclésiastiques" ".3) Dort heißt es nämlich am Schluß der Ausführungen über den rapt de séduction, daß dieser fast immer vorliege, wenn Personen unter 25 Jahren ohne Genehmigung ihrer Gewalthaber eine Ehe schließen, und daß darum der ganze Streit strenggenommen nur ein Streit um Worte sei. Wenn also, heißt es weiter, die Parlamente diese Ehen wogen rapt de séduction (und nicht wegen des Mangels der elterlichen Genehmigung) für ungültig erklären, so tun sie das aus Achtung vor dem kanonischen Rocht, welches im ersteren ein trennendes Ehehindernis sieht, im letzteren dagegen nicht.

Die "Conférences" zählen auch die Bedingungen auf, die zusammentreffen müssen, damit man von rapt de

1) Jean Gerbais, Traité pacifique du pouvoir de l'Église et des Princes sur les empêchemens du mariage, 2. édition, Paris 1696, p. 516 an. Ganz ähnlich die Conférences ecclésiastiques II p. 378 ss.

2) Gerbais p. 494; Conférences ecclés. II p. 423.

3) II p. $423 \mathrm{~s}$. 
duction sprechen könne. ${ }^{1}$ ) Die wichtigsten sind folgende zwei :

1. Die verführte Person muß minderjährig sein; großjährige Personen können nicht mebr Gegenstand einer Verführung hinsichtlich der Eheschließung sein. Das ergibt sich schon aus den einschlägigen Verordnungen, die immer nur von Minderjährigen reden. Auch stehen ja großjährige Kinder nicht mehr unter der Gewalt ihrer Eltern, und man kann darum nicht sagen, daß man sie diesen durch die Verführung wegnehme oder raube.

2. Die Verführung muß vollzogen werden ohne Wissen der Eltern. Der rapt de séduction ist ja nach den Grundsätzen des hl. Thomas und der Kanonisten eine Art Diebstahl gegenüber den Eltern und darum mit deren Wissen und Einverständnis nicht möglich. Man kann auch gar nicht von Verführung reden, wenn das Kind sich zu einer Ehe entschließt, welche die Eltern ihm vorschlagen und anraten, weil ihnen dieselbe für das Kind wie für die Familie vorteilhaft zu sein scheint. Sollten also in einem Fall, wo das Einverständnis der Eltern mit der Ehe gegeben ist, positive Beweise für eine Verführung vorliegen, so wäre denselben doch weiter keine Beachtung zu schenken.

\section{$\S 8$.}

Die Gründe der französischen Sondergesetzgebung.

Es ist von Interesse, nach den Gründen zu suchen, welche $\mathrm{zu}$ der im vorausgehenden dargestellten Sondergesetzgebung in Frankreich geführt haben mögen.

Die unmittelbarste Ursache lag sicher in den unleugbaren Mißständen, die mit den klandestinen Ehen verbunden waren und allgemein beklagt wurden. Zur Beseitigung dieser Mißstände wurde von vielen Seiten, besonders auch von französischer Seite vorgeschlagen, man solle die Gültigkeit der Ehen Minderjähriger entweder überhaupt oder doch bis zur Vollendung etwa des 18. oder 20. Lebens-

1) II p. $384 \mathrm{ss}$. 
Dex Rapt de séduction als Ehehindernis n. gallikan. Kirchenr. 105

jahres von der Zustimmung der Gewalthaber abhängig machen. Das Konzil von Trient, welches, wie schon erwähnt, diese Frage sehr eingehend erörterte, glaubte indes an der Eheschließungsfreiheit der Kinder festhalten zu müssen, machte aber den klandestinen Ehen im eigentlichen Sinn ein Ende, indem es die öffentliche Eheschließung vor clem Pfarrer und zwei oder drei Zeugen unter Strafe der Ungültigkeit der Ehe vorschrieb. Damit waren die alten Mißstände im wesentlichen beseitigt; denn einerseits wurde der Bestand der Ehen und ihre Beweisbarkeit gesichert, und andererseits bewirkte die Formvorschrift eine gewisse Erschwerung der Eheschließung, womit auch einige Sicherung gegen vorschnelle, unüberlegte Eheschließung gegeben war.

Gleichwohl hielt man in Frankreich ganz entschieden an der Forderung des elterlichen Konsenses fest, selbst dann noch, als durc:h die Verordnung von Blois die tridentinische Eheschließungsform auch für Frankreich wenigetens im wesentlichen eingeführt worden war. Welche Gründe mag man wohl dafür gehabt haben?

Duguit') führt deren zwei an, nämlich den Einfluß des römischen Rechts und die Reformation mit ihren Lehren uiber den rein weltlichen Charakter der Ehe.

Was zunächst die Reformation betrifft, so glaube ich nicht, daß dieselbe in so hohem Grade auf die Behandlung der Frage eingewirkt hat, wie Duguit und andere annehmen. Von einem direkten Einfluß wird schon deshalb schwerlich die Rede sein können, weil die französischen Könige wie auch die Parlamente der Reformation im allgemeinen durchaus feindselig gegenüberstanden, und weil sie gerade die reformatorische Lehre, daß die Ehe etwas rein Weltliches sei, nie anerkannten, sondern immer an dem sakramentalen Charakter derselben festhielten. Aber auch ein indirekter Einfluß reformatorischer Ideen dürfte in unserer Frage kaum nachzuweisen" sein.

Wesentlich anders liegt die Sache hinsichtlich des römischen Rechts. Dieses bildete, wie mir scheint, teils in sich, teils in der besonderen Ausgestaltung, die der eine oder

1) p. $601 \mathrm{ss.}$ 
andere seiner Grundsätze durch den Gallikanismus erhielt, so ziemlich ausschließlich die Veranlassung, daß der französische Staat überhaupt mehr und mehr zu einer selbständigen Gesetzgebung in Ehesachen überging, und da $B$ er insbesondere auch die Unentbehrlichkeit des elterlichen Konsenses bei der Ehe von minderjährigen Kindern unter allen Umständen festhalten zu müssen glaubte.

Von jeher war es den Juristen ein Dorn im Auge, daß die Kirche im Gegensatz zum Zivilrecht den minderjährigen Kindern die Möglichkeit gewährte, ohne Genehmigung ihrer Eltern eine gültige Ehe zu schließen. Lange Zeit hindurch mußten sie sich freilich in der Praxis mit dieser Regelung abfinden, aber ihre $\mathbf{A b}$ neigung und ihr Widerstand dagegen wurde doch immer größer und stärker, zumal in Frankreich, wo die politischen Verhältnisse zu einer Hebung der staatlichen Macht und Schwächung des kirchlichen Einflusses geführt hatten, so daß hier eher als anderswo Aussicht vorhanden zu sein schien, die Wünsche der Juristen durchzudrücken. Als nun im 16. Jahrhundert feststand, daß das Konzil von Trient eine gründliche Reform des Eherechts vornehmen müsse, traten vor allem die Juristen, insbesondere die französischen, dafür ein, daß die Gültigkeit der Ehen gewaltunterworfener Personen von der Zustimmung der Gewalthaber abhängig gemacht werden solle. Die französische Regierung machte sich, wie wir oben gesehen haben, diese Forderung ganz zu eigen, und man hoffte zuversichtlich, daß dieselbe erfüllt würde. Als nun die Entscheidung des Konzils wider Erwarten ablehnend ausfiel, wandten sich manche französische Juristen in der schärfsten Form dagegen, und wir haben hier wobl auch einen Grund mit, warum die Disziplinardekrete des Konzils in Frankreich nicht rezipiert wurden. Während der französische Klerus, der ursprünglich ebenfalls die Forderung der Regierung unterstützt hatte, sich schließlich der Entscheidung des Konzils fügte, drangen die Juristen von nun an fortwährend in die Könige, sie sollten ihrerseits den Mangel des elterlichen Ehekonsenses zu einem trennenden Ehehindernis erheben, eine Forderung, die, wie wir gesehen haben, von 
Der Rapt de séduction als Ehehindernis n. gallikan. Kirchenr. 107

den Königen zwar der Sache nach, nicht aber der Form nach erfüllt wurde.

Wenn so überhaupt das gesamte Vorgehen der französischen Gesetzgebung veranlaßt war durch die Anschauungen, welche die Juristen aus dem römischen Recht geschöpft hatten, so läßt sich der Einfluß dieses Rechtes auch im einzelnen vielfach nachweisen. Vor allem legte man in Übereinstimmung mit demselben auch in Frankreich das Hauptgewicht beim raptus nicht auf die Verletzung der Persönlichkeit der Entführten, sondern auf die Verletzung der elterlichen Autorität. Das geht so weit, daß man wenigstens vereinzelt die Ansicht vertrat, das Verbrechen und das Ehehindernis des raptus liege dann nicht vor, wenn die Entführung einer minderjährigen Person zwar gegen deren Willen, aber mit Zustimmung der Eltern erfolgte. ${ }^{1}$ ) Ebenso stammt die Rechtsvermutung, daß bei Zustimmung der Minderjährigen zur EheschlieBung ohne Konsens der Eltern Verführung vorliege, ganz sicher aus dem römischen Recht. Das gleiche gilt bezüglich der Todesstrafe für den Entführer, und wenn man liest, daß dieselbe zu vollstrecken sei "sans esperance de grace et de pardon", so denkt man unwillkürlich an die Bestimmungen Konstantins und Justinians, daB dem verurteilten raptor jede Appellation versagt sein solle.

Die Juristen machten übrigens auch gar kein Hehl daraus, daß das französische Recht in der Auffassung und Behandlung des raptus in weitgehendem $\mathrm{MaB}$ dem römischen Recht folgte, in mancher Beziehung über dasselbe hinausging, in anderen Punkten hinter ihm zurückblieb. ${ }^{2}$ )

Einen wertvollen Bundesgenossen fand das römische Recht im Gallikanismus, der seinerseits freilich wieder zu einem guten Teil auf jenes Recht zurückgeht. Der Gallikanismus war unter anderem besonders darauf bedacht, die völlige Unabhängigkeit der staatlichen Gewalt von der Kirche sicherzustellen und jeden auch nur indirekten Ein-

1) Hier läge allenfalls das Fhehindernis des Zwanges vor, aber nicht das der Entführung; vgl Durand de Maillane IV p. 238.

8) Oben S. 61 $95^{1}, 66^{1}$. 
fluß der Kirche auf das weltliche Gebiet auszuschalten; dagegen sollten umgekehrt alle Äußerungen des kirchlichen Lebens der staatlichen Aufsicht interstehen.

Wenn nun das römische Recht gegenüber der kirchlichen Lehre, daß die Ehe als Sakrament ganz und ausschließlich der Kirche unterstehe, sich darauf berief, daß rlie Ehe wesentlich auch Vertrag sei und darum wie jeder andere Vertrag dem Einfluß der weltlichen Gewalt unterliegen müsse, so verstärkte der Gallikanismus diese Beweisführung, indem er lehrte, daß die Gesetzgebung und die Rechtsprechung über die Ehe als solche, d. h. über das Eheband, wenigstens indirekt auch auf die bürgerlichen Wirkungen der Ehe Einfluß habe und schon deshalb nur dem Staat und nicht der Kirche zustehen könne, da ja der Kirche jede direkte oder auch nur indirekte Einwirkung auf weltliche Angelegenheiten versagt sei gemäß dem Worte C'hristi: „Mein Reich ist nicht von dieser Welt."

Ein weiterer Grundsatz des Gallikanismus besagte, wie eben bemerkt wurde, da $\beta$ das gesamte kirchliche Leben im Lande der Oberaufsicht des Königs unterstehe. Daraus folgerte man für diesen das Recht, die Disziplin der gallikanischen Kirche zu regeln, kirchliche Gesetze, die ihm ungeeignet ersclienen, abzulehnen oder zu verbessern, endlich etwaige Lücken der kirchlichen Gesetzgebung durch eigene Verordnungen auszufüllen. Desgleichen ergab sich daraus das Recht des Königs, von allen Akten der kirchlichen Verwaltung und Rechtsprechung Kenntnis zu nehmen und sie, wenn sie nach seiner Auffassung mit dem öffentlichen Wohl oder mit den alten Kanones in Widerspruch standen, für ungültig zu erklären oder durch seine Gerichte für ungültig erklären zu lassen. Fühlte sich ein Cntertan des Königs durch eine solche kirchliche Entscheidung beschwert, so konnte er beim Parlament appel comme d'abus einlegen und dadurch sein Recht beim staatlichen Gerichte suchen, das dann in letzter Instanz entschied.

Nach diesen Grundsätzen war es dem Staat unschwer möglich, auch hinsichtlich der Notwendigkeit des elterlichen Ehekonsenses seinen Willen gegenüber der Kirche durchzusetzen. Sie hätten es gestattet, den Mangel jenes Kon- 
Der Rapt de séduction als Ehehindernis n. gallikan. Kirchenr. 109

senses direkt zum trennenden Ehehindernis zu erheben. Wenn man das nicht tat, sondern lieber den Umweg über den raptus, der auch ein kirchliches Ehehindernis bildete, wählte und beibehielt, so entsprach das ganz dem Wesen des Gallikanismus, der durchaus kein grundsätzlicher Gegner der Kirche sein will, sondern nur danach strebt, sie zu beherrschen und ihren Einfluß auf das Volk unmittelbar den staatlichen Interessen dienstbar zu machen.

Zusammenfassend können wir über die französische Gesetzgebung bezüglich des elterlichen Ehekonsenses sagen: Das römische Recht mit seiner Auffassung von der Unbeschränktheit der väterlichen Gewalt und der absoluten Notwendigkeit der elterlichen Ehegenehmigung stellte die treibende Kraft dar, der Gallikanismus aber half als getreuer Sekundant mit, die Hindernisse wegzuräumen, welche eine starke, einflußreiche Kirche der praktischen Verwirklichung jener Anschauung des Zivilrechtes in den Weg gelegt haben würde. 